\title{
On the detection of the solar signal in the tropical stratosphere
}

\author{
G. Chiodo ${ }^{1}$, D. R. Marsh $^{2}$, R. Garcia-Herrera ${ }^{1,3}$, N. Calvo ${ }^{1}$, and J. A. García ${ }^{4}$ \\ ${ }^{1}$ Dpto. de Astrofísica y CC de la Atmósfera, Universidad Complutense de Madrid, Madrid, Spain \\ ${ }^{2}$ Atmospheric Chemistry Division, National Center for Atmospheric Research, Boulder, CO, USA \\ ${ }^{3}$ Instituto de Geociencias IGEO (CSIC-UCM), Madrid, Spain \\ ${ }^{4}$ Dpto. de Física, Universidad de Extremadura, Badajoz, Spain
}

Correspondence to: G. Chiodo (gchiodo@ucm.es)

Received: 8 October 2013 - Published in Atmos. Chem. Phys. Discuss.: 18 November 2013

Revised: 21 March 2014 - Accepted: 14 April 2014 - Published: 2 June 2014

\begin{abstract}
We investigate the relative role of volcanic eruptions, El Niño-Southern Oscillation (ENSO), and the quasibiennial oscillation (QBO) in the quasi-decadal signal in the tropical stratosphere with regard to temperature and ozone commonly attributed to the $11 \mathrm{yr}$ solar cycle. For this purpose, we perform transient simulations with the Whole Atmosphere Community Climate Model forced from 1960 to 2004 with an $11 \mathrm{yr}$ solar cycle in irradiance and different combinations of other forcings. An improved multiple linear regression technique is used to diagnose the $11 \mathrm{yr}$ solar signal in the simulations. One set of simulations includes all observed forcings, and is thereby aimed at closely reproducing observations. Three idealized sets exclude ENSO variability, volcanic aerosol forcing, and QBO in tropical stratospheric winds, respectively. Differences in the derived solar response in the tropical stratosphere in the four sets quantify the impact of ENSO, volcanic events and the QBO in attributing quasi-decadal changes to the solar cycle in the model simulations. The novel regression approach shows that most of the apparent solar-induced lower-stratospheric temperature and ozone increase diagnosed in the simulations with all observed forcings is due to two major volcanic eruptions (i.e., El Chichón in 1982 and Mt. Pinatubo in 1991). This is caused by the alignment of these eruptions with periods of high solar activity. While it is feasible to detect a robust solar signal in the middle and upper tropical stratosphere, this is not the case in the tropical lower stratosphere, at least in a $45 \mathrm{yr}$ simulation. The present results suggest that in the tropical lower stratosphere, the portion of decadal variability that can be unambiguously linked to the solar cycle may be smaller than previously thought.
\end{abstract}

\section{Introduction}

The Sun-climate connection is a topic of high relevance since solar variability is one source of natural variability in the climate system. The $11 \mathrm{yr}$ solar cycle is a welldocumented mode of variation of solar activity. To date, observations have shown decadal variations in the climate system that are commonly attributed to the $11 \mathrm{yr}$ solar cycle (see review by Gray et al., 2010). A well-established decadal variability can be found in reanalysis data of stratospheric temperature (Crooks and Gray, 2005). An extended reanalysis data set from the European Centre for Medium-Range Weather Forecasts seems to confirm this pattern (Frame and Gray, 2010). A similar variability has also been found in stratospheric ozone in three independent satellite data sets (Soukharev and Hood, 2006).

In the tropical stratospheric domain $\left(25^{\circ} \mathrm{N}-25^{\circ} \mathrm{S}\right)$, these studies show that zonal mean temperature and ozone vary in phase with solar activity (i.e., a warming and an ozone increase are found during peaks in solar activity). The vertical structure of the observed positive response is composed of a double peak, with maxima in the upper stratosphere at $1-3 \mathrm{hPa}$ and tropical lower stratosphere (hereafter TLS) at $50-70 \mathrm{hPa}$, along with a minimum response in the middle stratosphere at 10-20 hPa (e.g., see Fig. 1 in Frame and Gray, 2010, for temperature, and Fig. 5 in Soukharev and Hood (2006)). While the upper stratospheric peak is well established and in agreement with theoretical expectations, the structure of the signal in the middle stratosphere and TLS is more uncertain, and far less understood. It has been suggested that a solar cycle modulation of tropical upwelling may be the dynamical mechanism originating the response in 


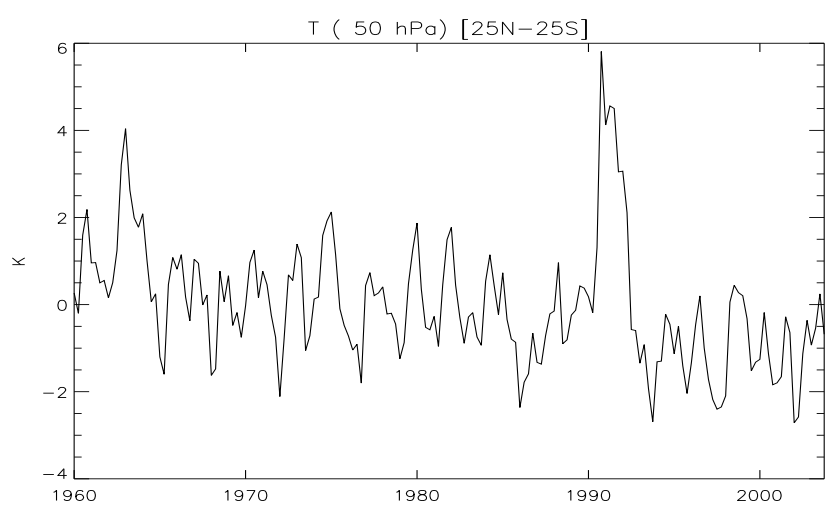

Figure 1. Time series of the simulated seasonal mean temperature anomalies at $50 \mathrm{hPa}$, averaged over the tropics $\left[25^{\circ} \mathrm{N}-25^{\circ} \mathrm{S}\right]$ in the reference "all forcings" set. Unit: K.

the TLS in ozone (Hood, 1997; Hood and Soukharev, 2003) and temperature (Kodera and Kuroda, 2002). However, this mechanism is linked to changes in wave driving of extratropical circulation, and it is mainly operative in the winter stratosphere, where the strong variability therein makes the detection of such changes extremely challenging.

Chiodo et al. (2012) reported good agreement in the simulated vertical profile of the solar signal from the Whole Atmosphere Community Climate Model (WACCM), version 3.5, and observations. WACCM3.5 is a general circulation model with a well-resolved stratosphere and interactive chemistry. Reasonable agreement was also found in other models of similar characteristics (Austin et al., 2008; Schmidt et al., 2010). However, the ability of the models in reproducing the signal in the TLS appears to depend on the boundary conditions, and the elements necessary to reproduce such a signal are model dependent. For this reason, the role of additional sources of variability (e.g., El NiñoSouthern Oscillation (ENSO), or quasi-biennial oscillation (QBO) in those models that assimilate it) in the tropical lower-stratospheric solar signal is far from being understood. The detection of solar signals is also difficult considering their relatively small amplitude compared with other sources of variability. This is especially true in the TLS, where a substantial portion of interannual variability is controlled by the QBO in both ozone (Randel and $\mathrm{Wu}, 2007$ ) and temperature (Randel et al., 2009b). Another important driver for interannual variability in the TLS is ENSO (Calvo-Fernández et al., 2004; Randel et al., 2009a). Volcanic eruptions also lead to strong temperature and ozone changes in this region, where decreases of 5-10\% in ozone and a warming of more than $1 \mathrm{~K}$ after the Mt. Pinatubo eruption in 1991 were reported (Randel et al., 1995).

Solar signals in observations and transient simulations are usually quantified with multiple linear regression (MLR) models that include a linear trend term, and proxies for ENSO, QBO, and volcanic eruptions. Unambiguous attribu- tion using a MLR model requires the predictors to be orthogonal (i.e., that they are not cross correlated) and predictand time series to be serially uncorrelated. However, serial correlation in temperature and ozone exists within seasonal timescales (Tiao et al., 1990). Additionally, cross correlations between proxies may arise during certain epochs. This is the case for the QBO, which is characterized as the vertical profile of the equatorial zonal mean zonal wind. The zonal wind in the tropical stratosphere can potentially be affected by ENSO and in situ heating caused by volcanic aerosol. Thus, volcanic and ENSO signals are embedded in the QBO index. Hence, deviations from the basic assumptions limit the reliability of estimates from regression models, especially when using data that only cover a few solar cycles, as in the case of reanalysis and satellite data sets.

The only feasible approach to quantify aliasing in observational data is to assess the sensitivity of the derived solar regression coefficients to the formulation of the regression model. This is the method used by some authors (Frame and Gray, 2010; Soukharev and Hood, 2006; Hood et al., 2010), who claimed that their solar regression coefficient is not affected by aliasing because of the very small changes when including ENSO, QBO, and volcanic terms in their regression model.

On the other hand, when using a climate model, the sensitivity of the simulated solar signal to the presence of other boundary conditions can be directly tested. This was done in simulations with a 2-D chemistry transport model (Smith and Matthes, 2008; Lee and Smith, 2003). Smith and Matthes (2008) showed that the simulated solar signal in tropical ozone strongly depends on the presence of the QBO. They showed that this dependence is indicative of a contamination of the solar signal by the QBO, and that the aliasing is mainly due to irregularities (i.e., departures from a sinusoidal function) in the observed QBO. In an earlier study using the same 2-D model, Lee and Smith (2003) found that volcanic eruptions have a similar effect, and that both QBO and volcanic signals equally alias on the observed structure of the ozone solar response. However, one may argue that such simplified 2-D models lack a full description of wave-mean-flow interactions that have been proposed to explain the origin of the decadal changes in the TLS.

Marsh and Garcia (2007) used a more comprehensive model to investigate tropical ozone decadal variability (WACCM3.1, Garcia et al., 2007). They found that the ozone solar signal in the TLS could only be reproduced by WACCM3.1 when observed SSTs were prescribed. They demonstrated that part of the ozone solar signal simulated in transient WACCM simulations was due to spurious correlation between the index for the solar cycle and ENSO over the 1979-2003 period. These conclusions were obtained by contrasting transient WACCM3.1 simulations performed with observed SSTs with time-slice experiments performed with climatological SSTs. Nevertheless, neither of these simulations included the radiative effects of volcanic eruptions, 
or a QBO. Thus, their results cannot be directly compared to observations.

There is clearly a need for a quantitative estimate of the portion of the decadal signals in the stratosphere that can unambiguously be linked to the solar cycle. It has been demonstrated that a warming in the TLS, such as that commonly attributed to the solar cycle, can trigger changes in tropospheric circulation (Haigh and Blackburn, 2006). Consequently, a correct attribution of changes in the TLS may in turn improve our understanding of the role of external forcings on tropospheric and surface climate that propagate downward from the stratosphere.

In this paper, we quantify the impact of the presence of other forcings on the detection of the $11 \mathrm{yr}$ solar cycle signal in simulations of the WACCM3.5 version including more realistic forcing than in previous studies. WACCM3.5 is a valuable tool for this exercise, since it has been previously shown that this model version is able to reproduce most features of the apparent $11 \mathrm{yr}$ solar cycle observed in the tropical stratosphere over the last several decades (Chiodo et al., 2012).

We compare the amplitude of the solar signal in simulations with all observed forcings to those where a single forcing has been excluded. Differences between the simulations quantify the impact of the exclusion of each forcing on the apparent solar signal, and thus the potential aliasing from the respective sources. The solar signal is diagnosed using a novel MLR approach, which reduces the autocorrelation and improves the accuracy of the regression fit through the use of an optimal lag in the predictors.

The paper is arranged as follows. Section 2 provides a description of the model and the experimental setup, along with the statistical methods employed in the analysis. The results are outlined in Sect. 3. Section 3.1 is dedicated to the relationship between each forcing and the simulated temperature and ozone variations. In Sect. 3.2, focus is then directed towards the $11 \mathrm{yr}$ solar cycle signal. The robustness of the apparent solar signal in the reference case is assessed in Sect. 3.3. A general discussion of the results and their implications is given in Sect. 4, while Sect. 5 summarizes the main results and conclusions.

\section{Data and methodology}

\subsection{Model simulations}

WACCM3.5 is an improved version of the WACCM3.1 general circulation model (Garcia et al., 2007). The standard resolution of 66 vertical levels ranging up from the surface to the thermosphere $(140 \mathrm{~km})$ and $1.9^{\circ}$ latitude by $2.5^{\circ}$ longitude in the horizontal was used in this work. This is the same model version that participated in the CCMVal-2 activity (CCMVal-2, 2010). Details of the model relevant for simulating the $11 \mathrm{yr}$ solar cycle are discussed in Chiodo et al. (2012).
We performed pairs of simulations of WACCM3.5 model run from 1960 to 2004. The setup of one pair is identical to the REFB 1 type of simulation presented in Eyring et al. (2010) for a comparison with other chemistry climate models and in Chiodo et al. (2012) for a detailed analysis of the $11 \mathrm{yr}$ solar cycle signal. This ensemble is referred to as "all forcings" due to the inclusion of all known natural and anthropogenic forcings. The forcings include observed SSTs and sea-ice concentrations (Hurrell et al., 2008), loadings of GHGs and ozone-depleting substances. Model equatorial stratospheric winds are relaxed toward observed winds to obtain a realistic time-varying QBO (Matthes et al., 2010). The effects of volcanic eruptions are included by prescribing aerosol surface area densities (SAD), compiled from a combination of Stratosphere Aerosol and Gas Experiment (SAGE) measurements (Thomason et al., 1997) and Solar Mesosphere Explorer (SME) instruments from 1979 onward. Aerosol data before 1979 are constructed based on assumptions of background aerosol (CCMVal-2, 2010). The impact on the heating rates in the stratosphere is explicitly calculated (Tilmes et al., 2009). The $11 \mathrm{yr}$ solar cycle in solar irradiance is introduced in the model by prescribing spectral irradiance data modeled by Lean et al. (2005), integrated over specific model bands for radiation and chemistry calculations. This set of simulations is aimed at closely reproducing observed interannual variations in the tropical stratosphere, and serves as a reference case.

In the second set of experiments, named "fixedSSTs", a climatological seasonal cycle of the SSTs is prescribed, thus removing ENSO from possible sources of variability in the stratosphere. In the next set, called "noQBO", the tropical stratospheric winds are not relaxed towards observations. Since the model version used in this work does not spontaneously generate a $\mathrm{QBO}$, permanent weak easterlies in the tropical stratosphere are simulated. Finally, the fourth set, named "noVOLC", is forced with a constant seasonal cycle of SAD, thus excluding peaks in sulfate aerosol concentrations in the stratosphere due to volcanic eruptions. The list of experiments is given in Table 1.

\subsection{Analysis method}

Monthly mean output is averaged over the two realizations done for each of the four sets, season (DJF, MAM, JJA, SON), longitude, and the $25^{\circ} \mathrm{N}-25^{\circ} \mathrm{S}$ latitude band. The tropical average seasonal mean anomalies are used as input for an improved MLR technique, whose formulation is novel in the context of solar cycle studies. Details are described in the Appendix and are briefly outlined below.

First, the autocorrelation is removed following a BoxJenkins prewhitening procedure (Box and Jenkins, 1980). This is applied to the time series of the seasonal means of the simulated ozone and temperature and of the predictors (i.e., the forcings used in each set). Next, lags are calculated that maximize the absolute value of the correlation between 
Table 1. Table of the WACCM3.5 ensembles performed.

\begin{tabular}{lclll}
\hline Name & \multicolumn{1}{c}{ SSTs } & QBO & Volcanoes & Solar \\
\hline "all forcings" (2) & observed, Hurrell et al. (2008) & assimilated, Matthes et al. (2010) & SAGE II, Thomason et al. (1997) & Lean et al. (2005) \\
"fixedSSTs"(2) & $\begin{array}{l}\text { climatological } \\
\text { assimilated, Matthes et al. (2010) }\end{array}$ & SAGE II, Thomason et al. (1997) & Lean et al. (2005) \\
"noQBO" (2) & observed, Hurrell et al. (2008) & none (weak east) & SAGE II, Thomason et al. (1997) & Lean et al. (2005) \\
"noVOLC" (2) & observed, Hurrell et al. (2008) & assimilated; Matthes et al. (2010) & climatological & Lean et al. (2005) \\
\hline
\end{tabular}

the prewhitened field variable and the forcings. In this way, the projection of the field variable onto the forcings in each set is maximized. These steps have been extensively used in the formulation of multiple linear regression models in other fields (e.g., in biometeorology (Diaz et al., 2002a, b) and economic forecasting (Bisgaard and Kulahci, 2011)), though they are new in the analysis of the $11 \mathrm{yr}$ solar signal.

The suitable lag for each predictor must be chosen with care. Ideally, the lag correlations should represent a physically consistent relationship between the predictand and predictors. On the other hand, such lags should not bring different predictors into phase, thereby increasing collinearity. With these criteria in mind, an optimal window, over which the suitable lag is searched for, is identified.

In our analysis, we use zonal wind time series at 30 and $10 \mathrm{hPa}$, which serve as QBO indices in the regression. By using the residual of a regression of the zonal wind onto other indices, the QBO indices become orthogonal to the other predictors. We exclude any lags in the QBO term itself in order to keep the mutual phase relationship in both indices (see Appendix). We find that by using this technique, the cross correlation among the QBO indices and the other predictors never exceeds 0.06 , which ensures that the null hypothesis of no correlation cannot be rejected at the $99 \%$ confidence level.

Principal component analysis (PCA) has been used in previous studies to derive orthogonal QBO indices (Randel and Wu, 1996; Crooks and Gray, 2005; Frame and Gray, 2010). The mathematical orthogonality constraint can potentially limit the physical realism of the principal component associated with the QBO. For this reason, we believe that the residuals from a MLR at 30 and $10 \mathrm{hPa}$ are more directly linked to the original wind field at both heights, and thus more suited than principal components for representing the QBO variability in the MLR.

This procedure is repeated for each of the simulation sets for both temperature and ozone. The regression model formulated in Eq. (A6) is applied at constant pressure levels of the tropical stratospheric domain $(0.1-100 \mathrm{hPa})$.

The MLR includes only predictors for those forcings included in the specific set of experiments (e.g., no QBO term is used in the analysis of the noQBO set). Since the main focus of this paper is the detection of the solar signal in the tropical stratosphere, results from the regression analysis are only presented for the UV coefficient ( $\beta_{\mathrm{uv}}^{\prime}$ in Eq. A6). The coefficient has been scaled at all isobaric levels by 0.175 . This scaling factor is the 2- $\sigma$ value of the UV radiation index used in the MLR, which represents the peak-to-trough solar cycle variation in units of $\mathrm{W} \mathrm{m}^{-2} \mathrm{~nm}^{-1}$.

\section{Results}

Figure 1 shows the time series of the tropical average $\left(25^{\circ} \mathrm{N}-\right.$ $25^{\circ} \mathrm{S}$ ) seasonal mean anomalies of the zonal mean temperature at the $50 \mathrm{hPa}$ level from the "all forcings" set. A longterm cooling trend is evident, and the amplitude of approximately $-0.5 \mathrm{~K}$ per decade agrees with observations (Randel et al., 2009b). The trend is interrupted by positive peaks over $2 \mathrm{~K}$ in 1964 and $5 \mathrm{~K}$ in 1992, which are caused by two major volcanic eruptions, i.e., Agung and Mt. Pinatubo. Among these events, the Mt. Pinatubo eruption is the bestcharacterized eruption on records. These records show a 1$2 \mathrm{~K}$ warming in 1992 in the $50 \mathrm{hPa}$ global mean (Randel et al., 2009b), while anomalies over the tropical belt reach $3 \mathrm{~K}$ (see Fig. 1 in Tilmes et al., 2009). Compared to these values, WACCM tends to overestimate the heating caused by the sulfate aerosols associated with the Mt. Pinatubo eruption.

Before applying the MLR, the variables and the forcings are prewhitened with the autocorrelation coefficient of the field variables. Since the choice of the lag for the predictors is crucial to improve the regression fit, we first analyze the lag correlation between forcings and the simulated field variables temperature and ozone.

\subsection{Lag correlation analysis}

The optimal lag must ensure a physically consistent relationship between the prewhitened field variables and the forcings. For this purpose, the vertical structure of the lag correlation is analyzed in detail in order to identify a window representing a realistic timescale for the response in the selected variable to each of the applied forcings.

Figure 2 shows the vertical profile of the correlation of the tropical average seasonal mean temperature with UV radiation from the all forcings set, plotted as a function of the time lag in a window of $10 \mathrm{yr}(-5$ to +5$)$, thus covering an almost complete solar cycle. Correlations at positive lag values mean that variations in UV lead temperature changes. Although the prewhitening of the time series considerably 
$\mathrm{T}^{\prime}, \mathrm{UV}$ ' [all forcings]

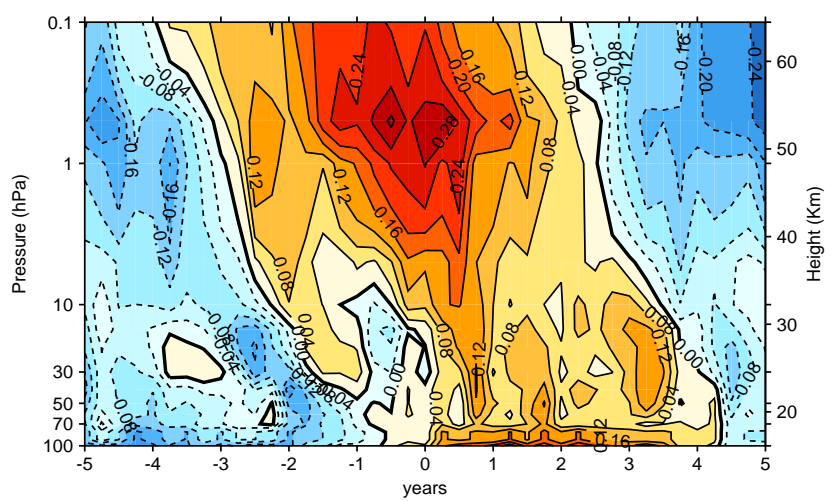

Figure 2. Lag correlation between the tropical average $\left[25^{\circ} \mathrm{N}-\right.$ $25^{\circ} \mathrm{S}$ ] prewhitened seasonal mean temperature from the all forcings case and the UV radiation index. Positive lags mean that UV predictor leads temperature changes. Solid contours and red colors denote positive correlations, while dashed contours and blue colors indicate negative correlations. Contours are drawn every 0.04 .

reduces the magnitude of the correlations, a well-defined positive temperature-UV relation is found at $1 \mathrm{hPa}$, which lingers for $2 \mathrm{yr}$ around the peak of solar activity (that is, from lag -1 yr to $1 \mathrm{yr}$ ). Negative values can be seen $5 \mathrm{yr}$ before and after the peak in UV radiation, indicating a cooling around minima of solar activity. Between 10 and $70 \mathrm{hPa}$, we identify positive maxima at lags of $0.75,1.75$, and $3.25 \mathrm{yr}$. Among them, the peak at $0.75 \mathrm{yr}$ corresponding to three seasons (or 9-11 months) seems to be connected to the upper stratosphere. This suggests that the warming induced by maxima in solar activity is instantaneous and longer-lasting in the upper stratosphere, whereas it is slightly weaker and delayed by a few seasons in lower layers.

Overall, the lag correlation to the UV in the WACCM simulations depicts a downward propagation of the solar signal. This is consistent with the "top-down" mechanism involving a downward pathway (which is thus mediated by the stratosphere) for solar influences to impact surface climate, as hypothesized in previous studies (Meehl et al., 2009; Gray et al., 2010). The broad time span of the maximum at $1 \mathrm{hPa}$ is most likely due to absorption of UV radiation whose peaks, on average over the recorded $11 \mathrm{yr}$ cycles 1923, last for about 2-3 yr (Lean et al., 2005). In lower levels, the intermittency of the positive correlations suggests a seasonality in the apparent downward propagation of the temperature signal. One candidate mechanism for such propagation is the strengthening of the wintertime polar night jet during solar maxima, which causes suppressed tropical upwelling (Kodera and Kuroda, 2002). This mechanism is captured by WACCM (Chiodo et al., 2012), and the timescales for the downward propagation are consistent with the lags found in the positive correlations of the $0-1 \mathrm{yr}$ window.

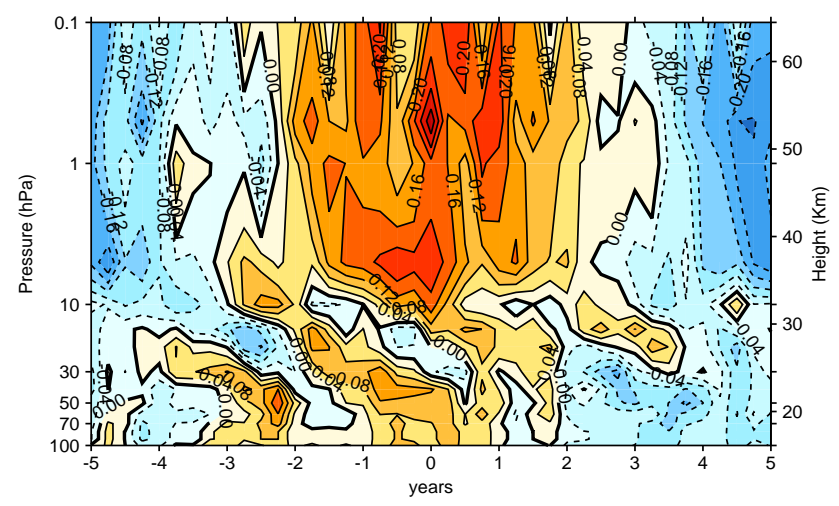

Figure 3. As in Fig. 2, for tropical mean zonal mean ozone from the all forcings case.

The lag correlation of UV radiation with tropical mean ozone is shown in Fig. 3. As it occurred in zonal mean temperature, a broad structure of positive ozone-UV correlations appears around lag 0 in the upper stratosphere $(0.1-10 \mathrm{hPa})$, with two peaks at 1 and $5 \mathrm{hPa}$. A more complex structure in the lag correlations is found in lower levels. At $10-50 \mathrm{hPa}$, there is a small region with negative values around lag 0 , while positive correlations appear at lags of $0.75-1 \mathrm{yr}$. At $50-100 \mathrm{hPa}$, positive correlations are found between 0 and $1 \mathrm{yr}$, maximizing at a lag of $0.25 \mathrm{yr}$, equal to one season. Except for the negative correlations at $30 \mathrm{hPa}$, there is good correspondence between temperature and ozone in the $0-1 \mathrm{yr}$ window.

The in-phase ozone-UV relationship in the middle and upper stratosphere is likely due to the UV-induced photolysis of molecular oxygen and recombination with atomic oxygen (Pap and Fox, 2004). This process is instantaneous, and extends for the $2-3 \mathrm{yr}$ of peak solar activity. As in temperature, the intermittency in the correlations at lower levels suggests a seasonality in the lower-stratospheric ozone response. In the $0-1 \mathrm{yr}$ span, the correspondence in the temperature and ozone correlations suggests that the same mechanism is controlling ozone and temperature responses in this window. Unlike in temperature, there is less evidence of a delayed response at lags larger than $1 \mathrm{yr}$ throughout the $30-100 \mathrm{hPa}$ region. This indicates that at such lags, it is difficult to link both temperature and ozone responses through a common mechanism.

Once we have analyzed the structure of the correlations, we next identify the optimal lag that maximizes the absolute value of the cross correlation with the UV index. We constrain the window over which the optimal lag is identified to the $0-1$ yr time span, motivated by the finding that a coherent variation in correlations with temperature and ozone was present in that interval. An added benefit of limiting the lag in the 0 to $1 \mathrm{yr}$ window is that the cross correlation between 
UV lag [all forcings]

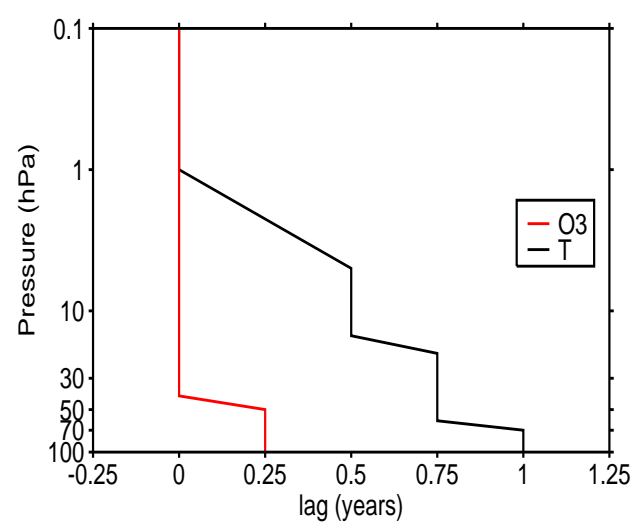

(a)

UV lag [noQBO]

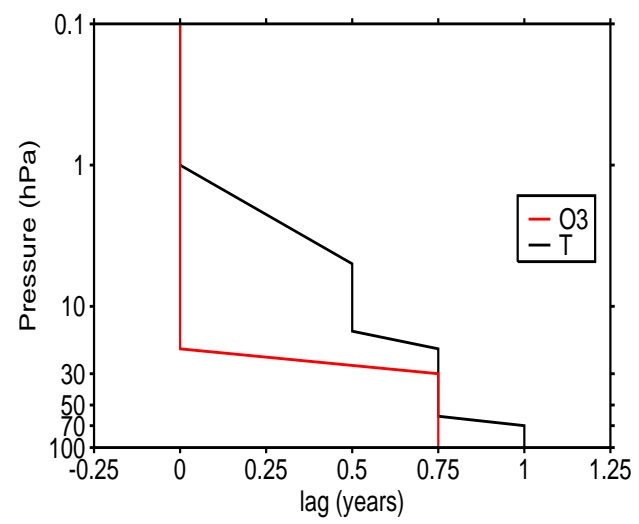

(c)
UV lag [fixedSSTs]

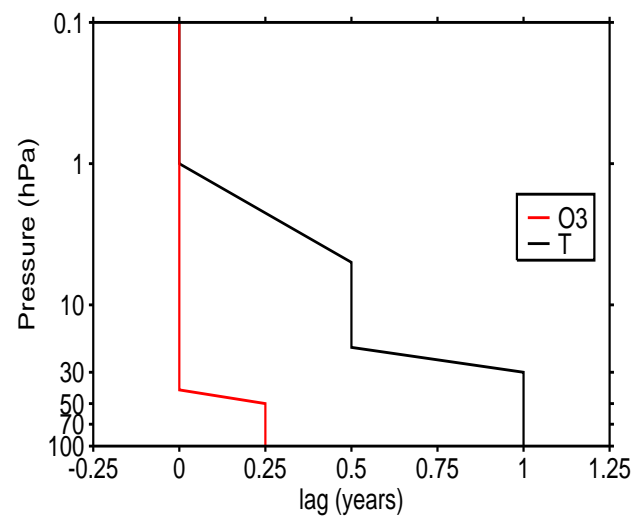

(b)

UV lag [noVOLC]

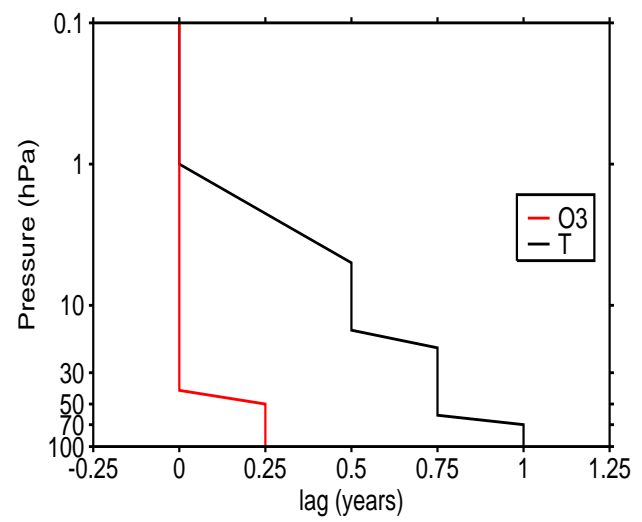

(d)

Figure 4. Vertical profile of the lag that maximizes the absolute value of the correlation (in the 0-1 years window) between UV radiation and prewhitened seasonal mean temperature (black) and ozone (red) from (a) the all forcings, (b) fixedSSTs, (c) noQBO, and (d) noVOLC sets. The values are introduced as $\tau_{i=u v}$ in Eq. (A6) for regression of tropical average temperature and ozone.

the UV index and the other predictors is minimized. Hence, the optimal UV lag ( $\left.\tau_{\mathrm{uv}}\right)$ to be used in Eq. (A6) is chosen in this window.

The vertical profile of $\tau_{\mathrm{uv}}$ is shown in Fig. 4 for zonal mean temperature and ozone. We show the values obtained for the all forcings case (a) and for the three idealized sets (b-d). Overall, the temperature-UV and the ozone-UV correlation patterns are found to be qualitatively similar in the three simulation sets excluding single forcings (not shown), which explains the similarity in the vertical profile of the optimal lag. In the case of zonal mean temperature, the profile shows a downward progression in all four cases, with a lag of $0.5 \mathrm{yr}$ (or two seasons) at $10 \mathrm{hPa}, 0.75 \mathrm{yr}$ (or three seasons) between 20 and $70 \mathrm{hPa}$, and $1 \mathrm{yr}$ between 80 and $100 \mathrm{hPa}$, consistent with the lagged positive correlation in this region seen in Fig. 2. In tropical ozone, the lag needed to maximize the correlation in the TLS is slightly smaller than in temperature, as seen in Fig. 3.

We also analyzed the lag correlation for the other terms included in Eq. (A6): the two QBO indices, N3.4 and SAD. As the present paper is focused on the solar response, we discuss it without showing additional figures. The cross correlation of temperature and ozone with $u 30^{\prime}$ and $u 10^{\prime}$ shows a downward-propagating pattern associated with the meridional secondary circulation of the imposed QBO (Baldwin et al., 2001). For the N3.4 index, negative correlations of 

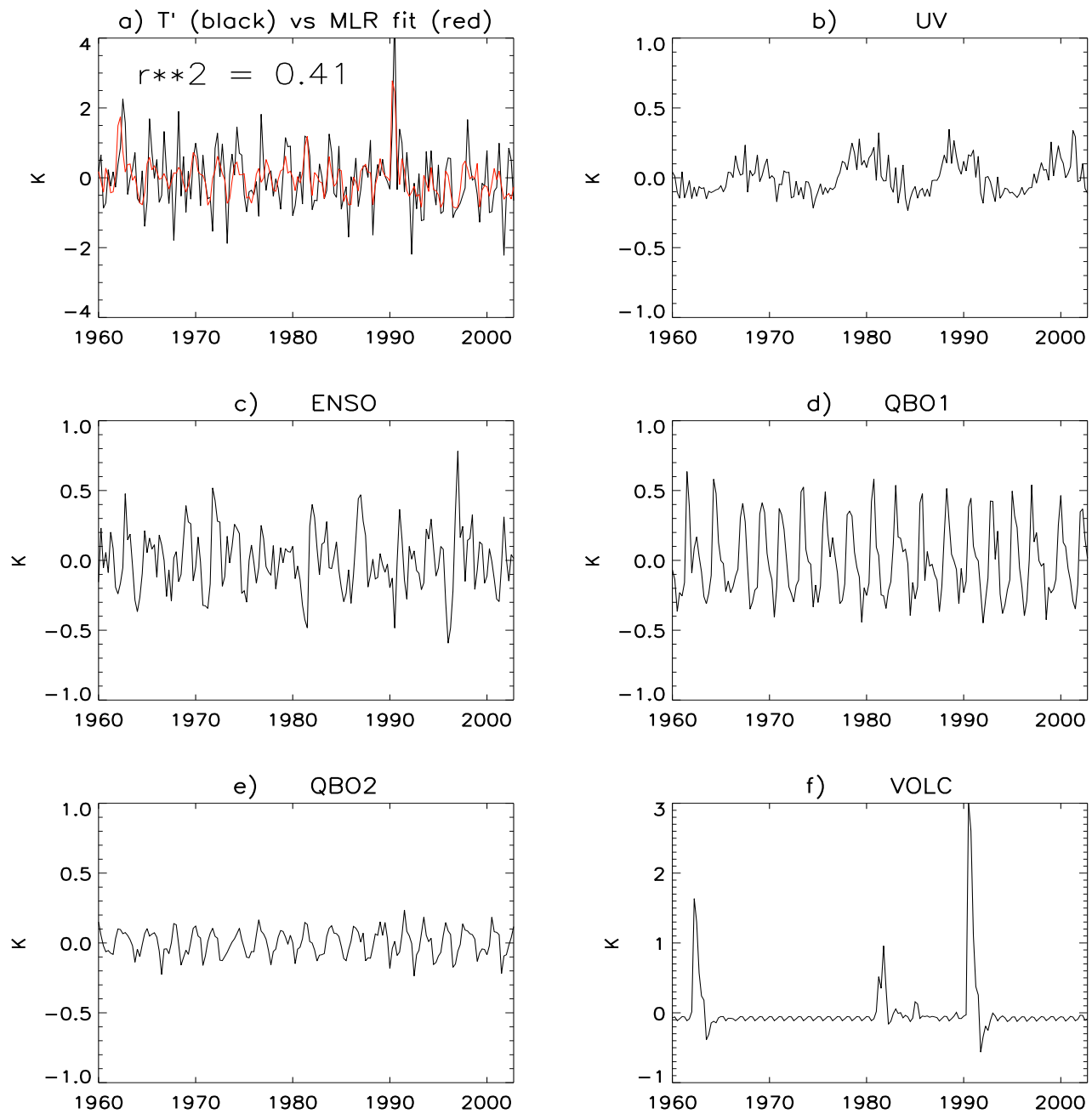

Figure 5. (a) Time series of tropical average seasonal mean zonal mean temperature anomalies at $50 \mathrm{hPa}$ after prewhitening (black), along with the regression fit from Eq. (A6) (red). (b-f) Contribution of each of the terms on the right-hand side of Eq. (A6) to the regression fit.

ozone and temperature maximize at $0.5 \mathrm{yr}$ (6-8 months, or two seasons) and $0.25 \mathrm{yr}$ (3-5 months, or one season), respectively, consistent with the lagged impact of El Niño on the TLS through an increase in tropical upwelling (Marsh and Garcia, 2007; Calvo et al., 2010). For the SAD index, we find positive correlations in temperature and negative values in ozone, both peaking at zero lag, and decaying as the lag increases to around $1.5 \mathrm{yr}$.

We constrained the optimal lag in the N3.4 and SAD indices to be no more than $1 \mathrm{yr}$, as was done for the UV index. This is motivated by the fact that at lags longer than $1 \mathrm{yr}$, spurious interference with the QBO appears in the form of downward-propagating QBO structures in both ozone and temperature correlations with N3.4 and SAD indices. Also, the cross correlation between N3.4, SAD, and QBO indices in the 0 to $1 \mathrm{yr}$ window is minimized. Hence, the optimal lag maximizing the correlation with these indices (i.e., $\tau_{\text {enso }}$ and $\tau_{\text {volc }}$ in Eq. A6) is chosen in this window.
We do not use a lag for the SAD index for the regression of both temperature and ozone, as the strongest correlation is found at zero lag. This implies that $\tau_{\mathrm{volc}}=0$ at all levels in Eq. (A6). For the N3.4 index, we use $\tau_{\text {enso }}=0.25 \mathrm{yr}$ (or one season) for the regression of temperature, while a value of $0.5 \mathrm{yr}$ (or two seasons) is used for ozone. No lags are used in $u 10^{\prime}$ and $u 30^{\prime}$, as the optimal fit is obtained by adjusting the relative weighting (i.e. regression coefficients) of these roughly sinusoidal variations. With these values for $\tau_{\text {enso }}, \tau_{\text {volc }}$ and those for $\tau_{\text {uv }}$ displayed in Fig. 4, a regression of the time series of zonal mean wind at 10 and $30 \mathrm{hPa}\left(u 10^{\prime}\right.$ and $u 30^{\prime}$ ) is performed (see Eq. (A5)). The residuals are then taken as QBO indices (i.e., $u 10^{*}$ and $u 30^{*}$ in Eq. (A6)).

An example of the application of the MLR procedure employed in this paper is given for the tropical average zonal mean temperature at $50 \mathrm{hPa}$, which is the time series shown in Fig. 1. Figure 5a shows the temperature time series after prewhitening, along with the fit output from the MLR 
Solar signal in zm T [25N-25S]

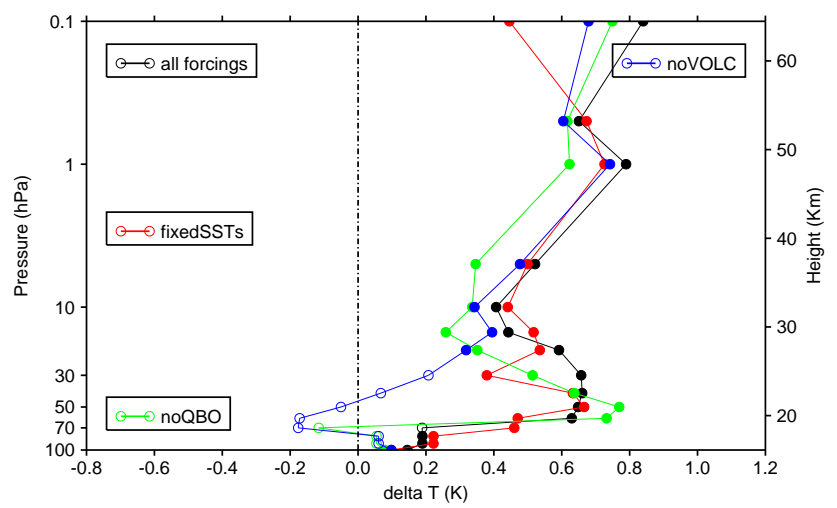

Figure 6. Solar signal in tropical average zonal mean temperature, estimated as the UV regression coefficient ( $\beta_{\mathrm{UV}}^{\prime}$ in Eq. (A6)) multiplied by 0.175 , which represents the $2-\sigma$ variation of the UV index used in the MLR. Delta K units denote the relative solar cycle peak to trough change in kelvin. Filled dots indicate that the derived regression coefficients are significantly different from 0 at the $2-\sigma$ significance level. The lags used for the UV index in each experiment set is the black line shown in Fig. 4.

model formulated in Eq. (A6). As seen in Fig. 4, the optimal UV lag $\left(\tau_{\mathrm{uv}}\right)$ used at this level is $0.75 \mathrm{yr}$ (or three seasons), while $\tau_{\text {enso }}=0.25 \mathrm{yr}$ (or one season). It is found that while the prewhitening smooths part of the variability, the peaks of the original time series shown in Fig. 1 are preserved. The $r^{2}$ value of 0.4 implies that $40 \%$ of the variability in the prewhitened temperature time series can be explained by the regression fit. Note that if no optimal lag is used for the predictors, the $r^{2}$ value would be 0.2 (not shown), which indicates a less accurate fit. Figure $5 \mathrm{~b}-\mathrm{f}$ plot the contribution of each term on the right-hand side of Eq. (A6) to the regression fit shown in Fig. 5a. The strongest temperature changes are caused by volcanic eruptions, with Mt. Pinatubo generating a $3 \mathrm{~K}$ anomaly (Fig. 5f). Changes of $0.5-1 \mathrm{~K}$ are associated with the first QBO term $\left(u 30^{*}\right.$, i.e., the filtered zonal wind at $30 \mathrm{hPa}$ ) and ENSO (Fig. 5c, d). On the other hand, the $11 \mathrm{yr}$ solar cycle signal is smaller, with temperature deviations of a few tenths of a kelvin (Fig. 5b).

\subsection{The 11 yr solar cycle signal}

The vertical profile of the solar signal, shown as the UV regression coefficient $\left(\beta_{\mathrm{uv}}^{\prime}\right)$ of the tropical average $\left(25^{\circ} \mathrm{N}-\right.$ $25^{\circ} \mathrm{S}$ ) zonal mean temperature scaled by $2 \sigma$ of UV radiation (0.175), is shown in Fig. 6. The profile is shown for the reference all forcings set, and the idealized experiments, using the optimal lag for the UV index shown in Fig. 4.

In the all forcings set (black line in Fig. 6), a statistically significant UV-induced warming is found throughout the tropical stratosphere, with maximum values of $0.8 \mathrm{~K}$ at $1 \mathrm{hPa}$ and a secondary maximum of $0.6-0.7 \mathrm{~K}$ at $40-50 \mathrm{hPa}$.
Solar signal in zm T [25N-25S]

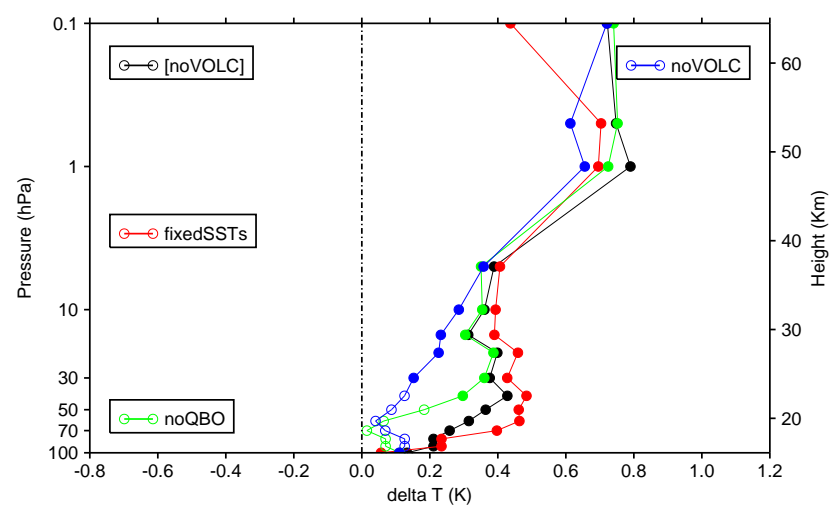

Figure 7. As in Fig. 6, calculated as the UV regression coefficient from a standard MLR ( $\beta_{u v}$ in Eq. (A1)) multiplied by 0.175 , which represents the 2- $\sigma$ variation of the UV index used in the MLR.

It is interesting to note that a statistically significant solar signal is also extracted in the middle stratosphere at 10 and $20 \mathrm{hPa}$, even though this is a region of relative minimum response. The lag used for the UV index is 0 at $1 \mathrm{hPa}, 6-8$ months (or two seasons) at $10 \mathrm{hPa}$, and 9-11 months (or three seasons) between 20 and $70 \mathrm{hPa}$ (see Fig. 4).

In the fixedSSTs case (red line in Fig. 6), the simulated temperature solar signal is similar to the reference case, although the secondary maximum at $50 \mathrm{hPa}$ is obtained at a slightly larger lag compared to the other sets $\left(\tau_{\mathrm{uv}}=1 \mathrm{yr}\right.$; see Fig. 4). The strong similarity in the derived UV regression coefficient in temperature suggests that the ENSO contribution to the apparent solar signal is negligible. The low sensitivity of the UV regression coefficient to the inclusion of ENSO is not due to the removal of the serial correlation, as similar results are obtained without prewhitening the data (not shown). The noQBO set (green line in Fig. 6) shows a significant solar response throughout the stratosphere above $60 \mathrm{hPa}$, with a peak of $0.7 \mathrm{~K}$ at $50 \mathrm{hPa}$. Overall, this profile resembles the reference all forcings case, although a slighly stronger magnitude of the warming is evident at $50 \mathrm{hPa}$. In the noVOLC set (blue line), a significant regression coefficient is obtained at all levels above $20 \mathrm{hPa}$, with a peak of $0.7 \mathrm{~K}$ at $1 \mathrm{hPa}$. However, below $20 \mathrm{hPa}$ the signal becomes weak and statistically insignificant. Thus, no robust solar response in temperature is obtained in the TLS in the WACCM simulations that do not include volcanic eruptions. The absence of response indicates that the apparent lagged temperature solar signal in the TLS diagnosed in all other simulation sets is associated with the effect of volcanic aerosols.

For comparison, the UV coefficient was also estimated from a standard MLR ( $\beta_{\mathrm{uv}}$ in Eq. (A1)). Figure 7 shows the vertical profile scaled by 0.175 . The temperature response in the upper stratosphere between 1 and $5 \mathrm{hPa}$ is very similar to that obtained with the new technique (Fig. 6); that 
Solar signal in zm O3 [25N-25S]

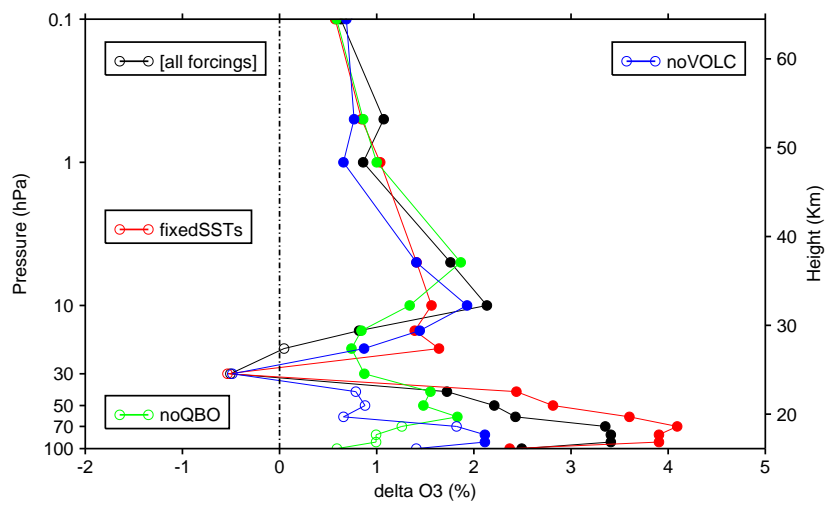

Figure 8. Solar signal in tropical average zonal mean ozone, estimated as the UV regression coefficient ( $\beta_{\mathrm{UV}}^{\prime}$ in Eq. (A6)) multiplied by 0.175 , which represents the $2-\sigma$ variation of the UV index used in the MLR. Delta \% units denote the relative solar cycle peak to trough change in percent (i.e., relative change in mixing ratio). Filled dots indicate that the derived regression coefficients are significantly different from 0 at the 2- $\sigma$ significance level. The lags used for the UV index in each experiment set is the red line shown in Fig. 4.

is, a significant warming of $0.6-0.8 \mathrm{~K}$ in all experiments. In the lower layers, there is less agreement between the ensembles. A secondary maximum is evident in the all forcings and fixedSSTs sets, with a peak of $0.4-0.5 \mathrm{~K}$ at $50 \mathrm{hPa}$. A similar response is also seen in the noQBO set, although the region of statistical significance is limited to higher altitudes $(20 \mathrm{hPa})$. Below $30 \mathrm{hPa}$, no significant response is seen in the noVOLC and noQBO ensembles. Comparing both techniques (i.e., Figs. 7 and 6), it is evident that the secondary maximum in the TLS extracted from the new regression technique, when statistically significant (i.e., in the all forcings and fixedSSTs sets), is stronger in magnitude than when using the standard MLR. Also, the new technique yields a secondary maximum in the noQBO set, whereas no response is seen in the standard MLR. Thus, in the TLS region the new regression method allows for better separation of the temperature solar signal from the QBO. The new method also shows a stronger reduction of the solar signal in the noVOLC set.

The new method was also applied to the tropical mean ozone mixing ratio. The vertical profile of $\beta_{\mathrm{uv}}^{\prime}$ scaled by 0.175 is shown in Fig. 8 in terms of relative solar cycle (\%) peak to trough change in the mixing ratio using the lag values for the UV index shown in Fig. 4. In the all forcings case, there is a well-defined double peak structure, with statistically significant ozone increase in the middle and upper stratosphere peaking at $2 \%$ at $10 \mathrm{hPa}$, a relative minimum at $30 \mathrm{hPa}$, and a significant increase at $40 \mathrm{hPa}$ and below, peaking at $3.5 \%$ between 70 and $90 \mathrm{hPa}$.

Fairly good agreement across all pairs of simulations is seen in the UV-induced ozone increase of $1.5-2.0 \%$ at 5-
Solar signal in zm O3 [25N-25S]

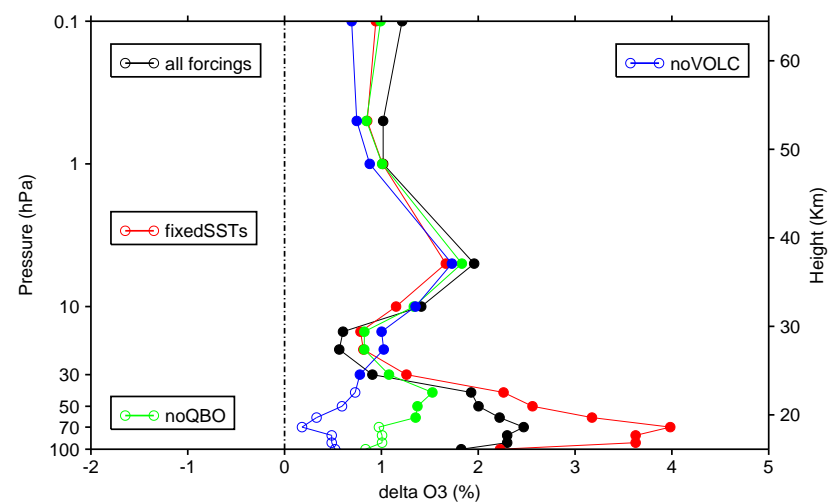

Figure 9. As in Fig. 8, calculated as the UV regression coefficient from a standard MLR ( $\beta_{\mathrm{uv}}$ in Eq. (A1)) multiplied by 0.175 , which represents the 2- $\sigma$ variation of the UV index used in the MLR.

$10 \mathrm{hPa}$, although the exact height of the maximum varies. At $20 \mathrm{hPa}$, the solar cycle ozone response in the noVOLC and noQBO case is slightly stronger than in the all forcings case. Reasonable agreement is also evident in the weakly negative response at $30 \mathrm{hPa}$, with exception of the noQBO case, which shows a positive and significant ozone response of $1 \%$.

Significant differences are evident in the amplitude of the ozone increase in the stratospheric levels between 40 and $100 \mathrm{hPa}$. While the all forcings case features a significant ozone increase ranging from $2.0 \%$ at $50 \mathrm{hPa}$ to $3.5 \%$ at $70 \mathrm{hPa}$, the response in the noVOLC case follows a similar profile, although with lower values ranging from a nonsignificant $0.8 \%$ increase at $50 \mathrm{hPa}$ to $1.5-2.0 \%$ at 70 $80 \mathrm{hPa}$. At $70 \mathrm{hPa}$ and below, a different response is also observed in the noQBO case, where a non-significant $1.0 \%$ ozone increase is obtained. On the other hand, the ozone response at $70-80 \mathrm{hPa}$ is increased to $4.0 \%$ in the fixedSSTs case, although the difference between this set and the all forcings pair of simulations is not statistically significant. Among all experiments, the profile of $\beta_{\mathrm{uv}}^{\prime}$ obtained from the fixedSSTs set is the one that most closely resembles the all forcings case in the lower stratosphere. Those calculated from the noVOLC and noQBO exhibit the largest differences to the reference case, with a weaker response throughout the lower stratosphere below $40 \mathrm{hPa}$ in the noVOLC case, and below $70 \mathrm{hPa}$ in the noQBO case. This suggests that part of the apparent lower-stratospheric ozone signal obtained from the all forcings case is due to QBO and volcanic aliasing, with the largest spurious contribution coming from volcanic aerosol.

Figure 9 shows the ozone UV regression coefficient obtained from a standard MLR ( $\beta_{\mathrm{uv}}$ in Eq. (A1)). The ozone increase of approximately $2 \%$ at $5 \mathrm{hPa}$ is similar to the response obtained from the new technique (Fig. 8). The relative minimum at $20 \mathrm{hPa}$ is statistically significant, while, using 

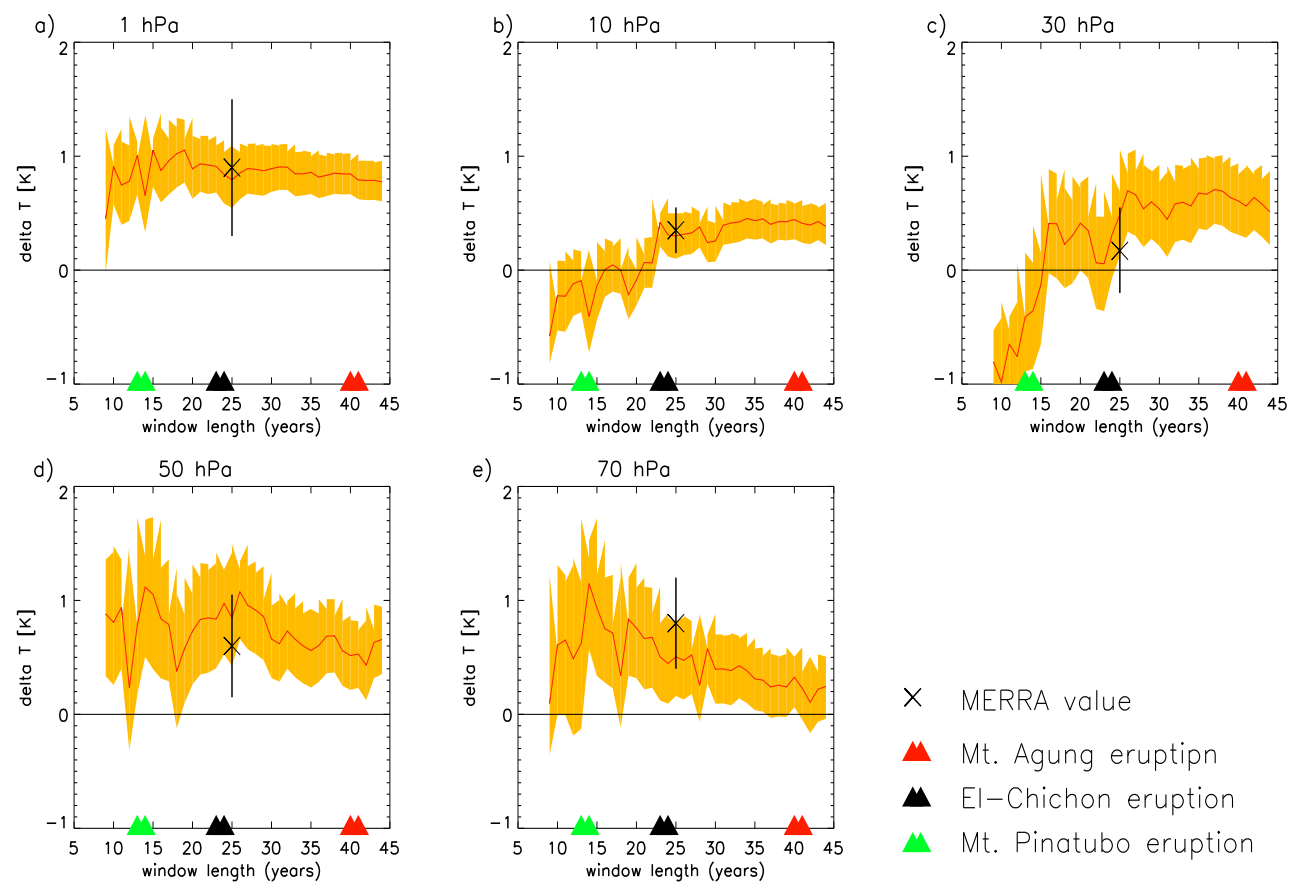

Figure 10. UV regression coefficient ( $\beta_{\mathrm{UV}}^{\prime}$ in Eq. (A6)) in tropical mean zonal mean temperature (red line) along with the 2- $\sigma$ uncertainty (yellow shading) from the all forcings case, plotted as a function of the window used (in years). The endpoint of the window is the last available year in the ensembles, i.e., 2004. Results are shown for (a) $1 \mathrm{hPa}$, (b) $10 \mathrm{hPa}$, (c) $30 \mathrm{hPa}$, (d) $50 \mathrm{hPa}$, and (e) $70 \mathrm{hPa}$. Crosses show the values obtained from MERRA reanalysis at 30, 50, and $70 \mathrm{hPa}$ using the window overlapping the simulation period (1979-2004). Unit: K.

the new MLR, this response is not significant and lower in altitude $(30 \mathrm{hPa})$. Both techniques show differences between ensembles in the region below $40 \mathrm{hPa}$, although the spread seems larger in the standard MLR. In the new MLR, the difference in the solar response between the all forcings and fixedSSTs sets at $50-70 \mathrm{hPa}$ is smaller compared to the standard MLR. This indicates that the use of the new regression technique reduces the ENSO aliasing in the apparent solar response of lower-stratospheric ozone. Overall, both techniques show a reduction of the solar signal below $30 \mathrm{hPa}$ in the noVOLC set compared to the all forcings set. Accordingly, the contribution of volcanic aerosol to quasi-decadal variability of tropical lower-stratospheric ozone does not depend on the type of regression analysis.

\subsection{Sensitivity of the solar signal to the data window}

The results from the idealized cases give useful information about the impact of other forcings on the analysis. However, these simulations might not be able to reproduce non-linear interactions between the missing forcing and the $11 \mathrm{yr}$ solar cycle. The aim of this section is thus to assess aliasing in the regression of one pair of simulations driven by the combination of forcings that most closely resembles the real atmosphere, as is the all forcings case. In this way, it is possible to quantify the potential aliasing in regressing a limited record, and in turn to infer the feasibility of extracting a robust so- lar signal from the window covered by observational records. One method to accomplish this consists of testing the sensitivity of the diagnosed signal to the length of the data.

We calculate the UV regression coefficient $\left(\beta_{\mathrm{uv}}^{\prime}\right)$ from the all forcings set for a varying data window, whose endpoint is the last year available in the simulations: 2004. A minimum of $10 \mathrm{yr}$ is used to cover the last solar cycle (1995-2004), and the data window is gradually extended to the whole 45 available years, using $1 \mathrm{yr}$ increments.

Figure 10 shows the estimates for tropical mean temperature, calculated at 5 different pressure levels representative of the upper stratosphere $(1 \mathrm{hPa})$, middle stratosphere $(10 \mathrm{hPa})$, and lower stratosphere $(30,50$, and $70 \mathrm{hPa})$, scaled by the $2-\sigma$ value of the UV index. Note that the endpoint value obtained with the entire $45 \mathrm{yr}$ time series is identical to that shown (on the same levels) in Fig. 6.

In the upper stratosphere at $1 \mathrm{hPa}$ (Fig. 10a), a constant value of $0.8-1.0 \pm 0.2 \mathrm{~K}$ is obtained. One can deduce that the minimum number of years necessary for extracting a significant and stable solar signal in temperature at $1 \mathrm{hPa}$ is 10 $15 \mathrm{yr}$, since the value obtained with such window is fairly close to that calculated with the full available period of $45 \mathrm{yr}$. At 10 and $30 \mathrm{hPa}$ (Fig. 10b, c), the regression coefficient is slightly negative and not significant when less than $20 \mathrm{yr}$ of data is used. It then stabilizes to a significant positive value of $0.4 \pm 0.2 \mathrm{~K}$ at $10 \mathrm{hPa}$ and $0.5 \pm 0.3 \mathrm{~K}$ at $30 \mathrm{hPa}$ when more than $25 \mathrm{yr}$ of data is used. 
At lower-stratospheric levels $(50$ and $70 \mathrm{hPa}$, shown in Fig. 10d, e), the derived values are more uncertain than in the upper stratosphere, as indicated by the wider error bars, and exhibit stronger sensitivity to the window length. Broadening the data window reduces the apparent signal at 50 and $70 \mathrm{hPa}$ from $1.0 \pm 0.7 \mathrm{~K}$ with $15 \mathrm{yr}$ of data to $0.2-$ $0.5 \pm 0.3 \mathrm{~K}$ when using the $45 \mathrm{yr}$ of data. No convergence towards a steady value is found at these levels. Thus, a stable and significant temperature response can only be detected above $30 \mathrm{hPa}$, while a different behavior is observed at 50 and $70 \mathrm{hPa}$, where no robust value can be extracted with the available 45 yr long record.

In addition, strong swings are evident in the middle and lower stratosphere $(30,50$, and $70 \mathrm{hPa})$ a few years after the occurrence of the two major volcanic eruptions when using WACCM data, suggesting that volcanic and solar signals cannot be cleanly separated by the regression model at these levels. Interestingly, both Mt. Pinatubo and El Chichón eruptions appear to interfere with the solar signal at 30 and $50 \mathrm{hPa}$. This is not the case at $70 \mathrm{hPa}$, where only the former has a discernible impact (Fig. 10e). There are also perturbations of negative sign when the Agung eruption (1963) is included in the analysis. This effect is seen at 50 and $70 \mathrm{hPa}$, although the jumps are much less evident than in the case of the other two eruptions. Overall, the peaks associated with Mt. Pinatubo and El Chichón disappear after $30 \mathrm{yr}$ of data is included in the regression analysis. Even when the analysis is extended using a longer window, the UV coefficient decreases at both levels, which is particularly evident at $70 \mathrm{hPa}$. This suggests that in WACCM3.5, no robust signal in temperature can be extracted in the TLS with $45 \mathrm{yr}$ of simulations data.

The UV regression coefficient is also estimated using the same procedure on NASA's Modern-Era Retrospective Analysis for Research and Applications (MERRA) reanalysis data (Rienecker et al., 2011), chosen here over other reanalysis products due to the larger overlap with the simulations (1979-2004). WACCM and MERRA can be directly compared by using $26 \mathrm{yr}$ as the window in the all forcings case. At this window length, the apparent solar signals at $1 \mathrm{hPa}$ (Fig. 10a) and $10 \mathrm{hPa}$ (Fig. 10b) of 0.8 and $0.3 \mathrm{~K}$ in the model simulations are in excellent agreement with MERRA estimates. Since the temperature response at these heights is related to the direct response to the UV radiation, the agreement with reanalysis suggests that the model sensitivity to the $11 \mathrm{yr} \mathrm{UV}$ forcing is realistic. There is also qualitative agreement at $30 \mathrm{hPa}$ (Fig. 10c), $50 \mathrm{hPa}$ (Fig. 10d), and $70 \mathrm{hPa}$ (Fig. 10e) in the signals of $0.3,0.5$, and $0.7 \pm 0.2 \mathrm{~K}$, respectively. However, this only applies to the $26 \mathrm{yr}$ window overlapping with MERRA since, as indicated above, a decrease in the diagnosed solar signal is seen as a larger analysis period is used.

It should be recalled that the warming simulated at $50 \mathrm{hPa}$ after Mt. Pinatubo in 1992 is too large (see Fig. 1). This bias might contribute to the misattribution of quasi-decadal vari- ability when using model data in the analysis. Accordingly, the impact on the detection of solar signals might depend on the size of the underlying volcanic signature. To test this possibility, we analyze the dependence of the solar signal to data windowing in the MERRA record, bearing in mind that less stability is expected due to the shorter window compared to the WACCM simulations. Figure 11 shows the regression coefficient obtained from MERRA, calculated in the same way as in Fig. 10, plotted as a function of the $26 \mathrm{yr}$ window. A robust signal is found at 1 and $10 \mathrm{hPa}$, with values of $0.9 \pm 0.5 \mathrm{~K}$ and $0.3 \pm 0.2 \mathrm{~K}$, respectively (Figs. 11a, b). The values at 30, 50 , and $70 \mathrm{hPa}$ (Figs. 11c, e) are less stable, which is in large part due to the peak coinciding with the Mt. Pinatubo eruption, especially at $50 \mathrm{hPa}$ (Fig. 11d). There is also a tendency towards smaller values at these levels, as the window gets broader, although a stable value is not reached. This suggests that, as in WACCM, the solar signal extracted over the available observational record is not robust, mainly due to the heating associated with the Mt. Pinatubo eruption.

Figure 12 shows the UV regression coefficient obtained from WACCM at 50 and $70 \mathrm{hPa}$, when periods after $\mathrm{El}$ Chichón and Mt. Pinatubo eruptions are omitted (June 1982November 1983 and September 1991-November 1993). During such periods, the peaks in lower-stratospheric temperature associated with the SAD index can be identified (see Fig. 5f). Convergence toward a constant value of approximately $0.1 \pm 0.3 \mathrm{~K}$ is obtained when more than $20 \mathrm{yr}$ of data is used. However, this value is not significantly different from zero. When the same years are excluded from the MERRA reanalysis data, the UV coefficient is also reduced from 0.6$0.7 \pm 0.3 \mathrm{~K}$ to $0.2 \pm 0.4 \mathrm{~K}$ at both 50 and $70 \mathrm{hPa}$. This indicates that when applying MLR methods on stratospheric temperature data covering $26 \mathrm{yr}$, a better separation of solar and volcanic signals can only be achieved with removal of data around both El Chichón and Mt. Pinatubo eruptions. This is consistent with the absence of a signal in the TLS in the set without volcanoes (blue line in Fig. 6). Note that the removal of the period after the Agung eruption (1963-1964) would not alter the results (not shown), which is consistent with the small impact of this event on the window sensitivity of the solar signal shown in Fig. 10.

The sensitivity to data windowing of the regression coefficient in zonal mean ozone simulated by WACCM is shown in Fig. 13. The ozone signal is robust to the extension of the data window at $1 \mathrm{hPa}$ (Fig. 13a), and a constant and significant ozone increase of $0.7 \pm 0.4 \%$ is found after $10 \mathrm{yr}$ of simulations data. At $10 \mathrm{hPa}$ (Fig. 13b), positive and significant values of $2.2 \pm 0.8 \%$ are found for all data windows, although jumps to higher values are evident when using less than $30 \mathrm{yr}$ of data. A significant positive UV coefficient is obtained at $30 \mathrm{hPa}$ when using less than $15 \mathrm{yr}$ of data (Fig. 13c). However, this signal is not real since no significant ozoneUV relationship is obtained with a larger data window. This is the region in which a relative minimum response in the vertical profile is obtained in all idealized experiments, although 

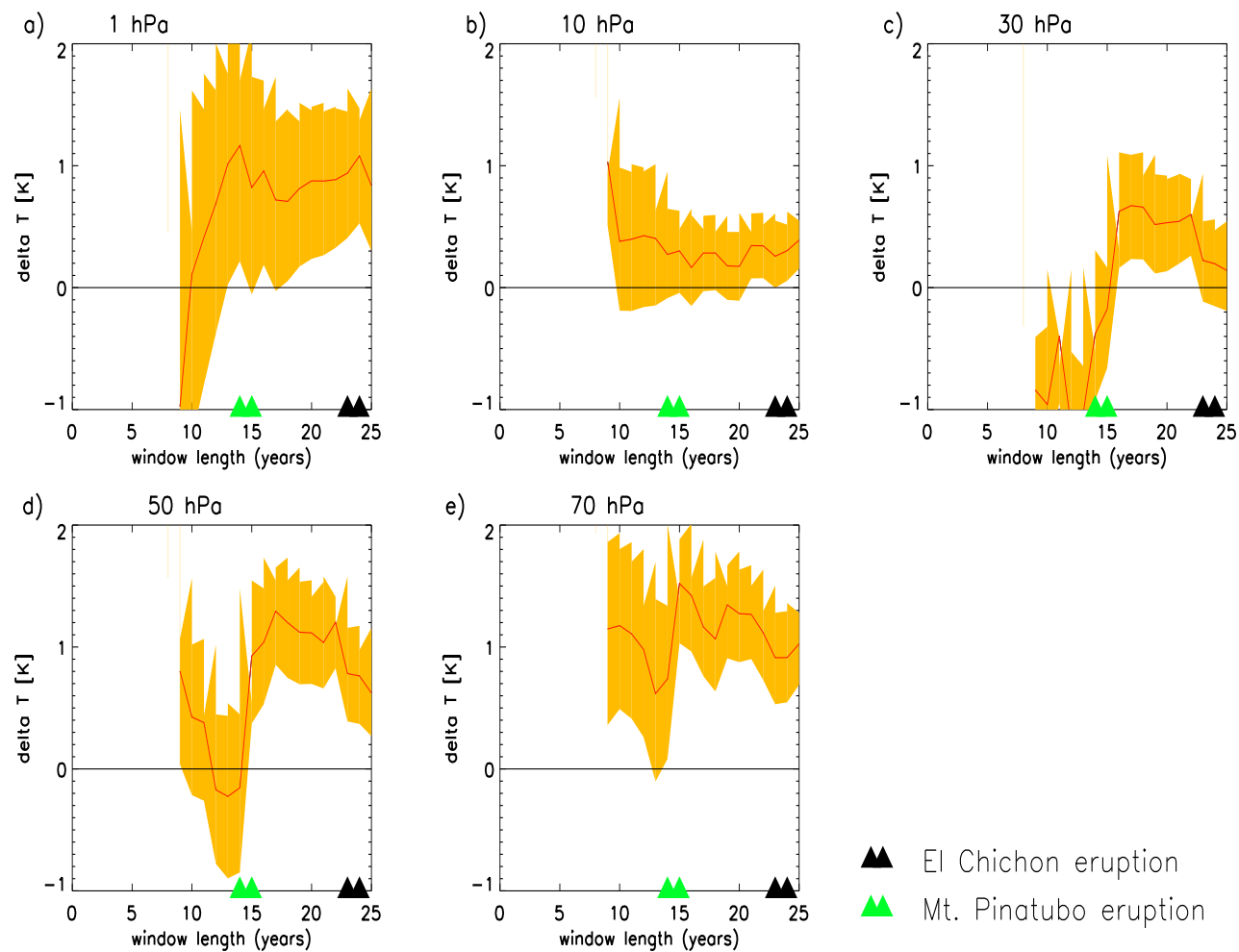

Figure 11. UV regression coefficient ( $\beta_{\mathrm{UV}}^{\prime}$ in Eq. (A6)) in tropical average zonal mean temperature from MERRA reanalysis, displayed as a function of the window used, which is $26 \mathrm{yr}$ long. Note that the signal has been computed with the same regression technique as in WACCM. The endpoint of the window is the last available year in the WACCM simulations, i.e., 2004. Unit: K.

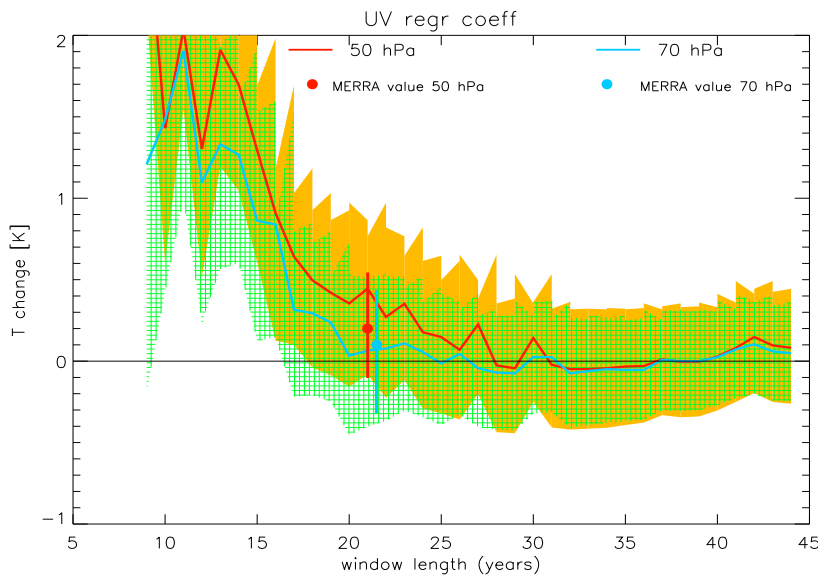

Figure 12. UV regression coefficient in tropical mean zonal mean temperature from the all forcings case, obtained when omitting post El Chichón and Mt. Pinatubo data (see exact dates indicated in the text), plotted as a function of the years included in the window. The endpoint of the window is the last available year in the ensembles, i.e., 2004. Results are shown for the $50 \mathrm{hPa}$ (red) and $70 \mathrm{hPa}$ (blue) levels, along with the 2- $\sigma$ uncertainty (yellow for $50 \mathrm{hPa}$ and green for $70 \mathrm{hPa}$ ). Dots indicate the values obtained from MERRA reanalysis, along with the 2- $\sigma$ uncertainty. Unit: K. with slightly different magnitudes (see Fig. 8). At $30 \mathrm{hPa}$, the noQBO experiment showed a significant ozone increase of $0.6 \%$ (see Fig. 8), which suggests that QBO aliasing reduces the apparent $11 \mathrm{yr}$ variation at this level.

At 50 and $70 \mathrm{hPa}$, a strong swing in the ozone UV response from negative to positive values is evident in proximity to the Mt. Pinatubo eruption in 1991 (Fig. 13d, e), which is indicative of the volcanic aliasing when regressing data of Mt. Pinatubo eruption. There is little evidence of aliasing in the wake of the El Chichón eruption in 1982 at $50 \mathrm{hPa}$. At this level, a rather constant and marginally significant value of $1.0-1.5 \pm 1.0 \%$ is diagnosed when more than $20 \mathrm{yr}$ of data is used.

At $70 \mathrm{hPa}$ (Fig. 13e), there is also a jump in proximity to the El Chichón eruption in 1982, although the strongest variation is seen in the years around Mt. Pinatubo (1991). Overall, volcanic eruptions have a stronger impact on the signal at 70 than at $50 \mathrm{hPa}$, which is consistent with the larger differences found at this level in the noVOLC set (Fig. 8). The error bars and the variations in the amplitude are larger than at higher levels, which suggests that it is not feasible with the available data to extract an accurate estimate for the ozone solar response at $70 \mathrm{hPa}$. Nevertheless, there is some evidence of a trend toward a positive signal of $3.2 \pm 1.8 \%$ as all available $45 \mathrm{yr}$ of data are included in the analysis. This 

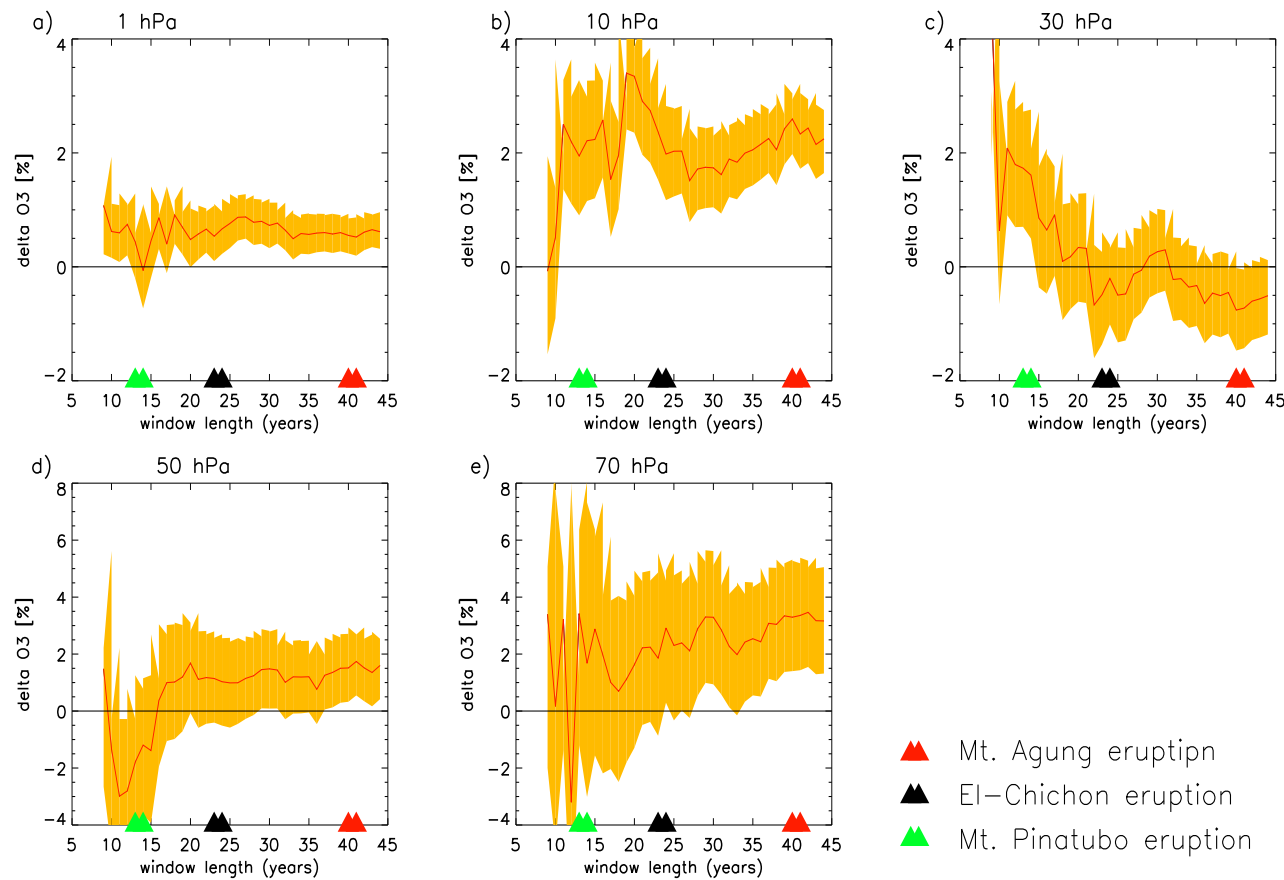

Figure 13. As in Fig. 10, for tropical mean zonal mean ozone. Unit: \%(i.e., relative change in mixing ratio).

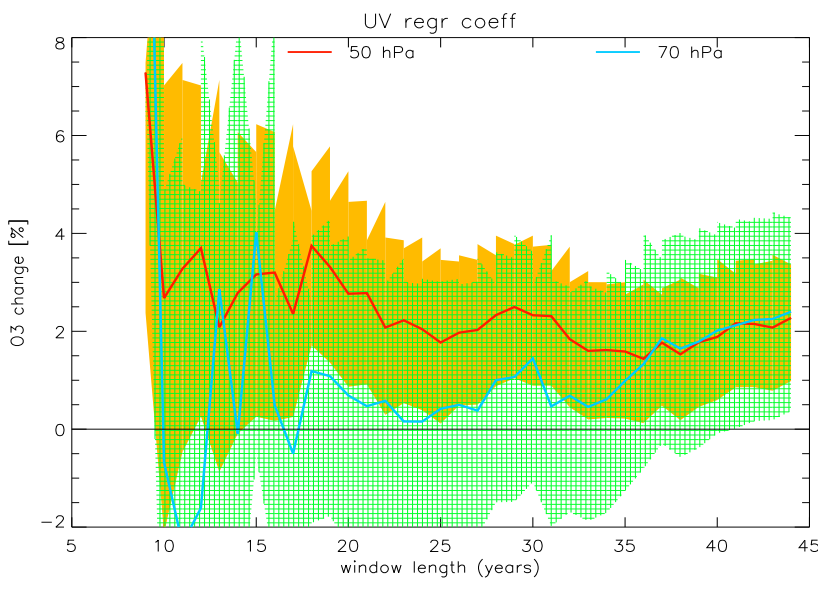

Figure 14. UV regression coefficient in zonal mean ozone from the all forcings case, omitting the post-El Chichón and Mt. Pinatubo data (June 1982 to November 1983, and September 1991 to November 1993), plotted as a function of the window used (in years) for $50 \mathrm{hPa}$ (red) and $70 \mathrm{hPa}$ (blue), along with the 2- $\sigma$ uncertainty (yellow shading for $50 \mathrm{hPa}$ and green shading for $70 \mathrm{hPa}$ ). The endpoint of the window is the last available year in the ensembles, i.e., 2004. Unit: percent.

behavior is unlikely to be related to the Agung eruption, since the tendency in the ozone solar signal starts at year 35, i.e., $6 \mathrm{yr}$ ahead of year 41 in the window, which would correspond to the eruption year 1963 .

Figure 14 shows the ozone UV coefficient calculated at 50 and $70 \mathrm{hPa}$, when the El Chichón and Mt. Pinatubo post- eruption data are omitted following the same procedure taken for temperature. A fairly constant value of $2.0 \pm 1.5 \%$ is obtained at $50 \mathrm{hPa}$ when using more than $25 \mathrm{yr}$ of data. These numbers are not significantly different from those shown in Fig. 13d, which were calculated with Mt. Pinatubo and El Chichón data retained. At $70 \mathrm{hPa}$, there is nearly no response at a window of 20-25 yr, and a positive trend towards positive values is evident when more than $35 \mathrm{yr}$ of data is used. The value of $2.3 \pm 1.9 \%$ obtained with the full $42 \mathrm{yr}$ window is lower than the $3.2 \pm 1.8 \%$, which was diagnosed without removing post-eruption data (Fig. 13e). This is consistent with the reduction in the apparent solar signal obtained from the noVOLC experiment at this level (Fig. 8).

Overall, temperature and ozone show slightly different sensitivities to data windowing, which probably owes to the different processes controlling their variations in the tropical stratosphere. Further complication is brought by the low signal-to-noise ratio in ozone due to the relatively small ozone concentrations below $50 \mathrm{hPa}$. Nevertheless, both variables suggest that a robust solar signal can only be extracted using an MLR technique at upper- and middle-stratospheric levels.

\section{Discussion}

The tropical mean vertical profile of the $11 \mathrm{yr}$ solar signal has been extracted from WACCM simulations using a novel MLR methodology. In the upper stratosphere, a $0.8 \pm$ $0.2 \mathrm{~K}$ warming is diagnosed, which agrees with MERRA 
and ERA-40/ERA-Interim estimates within the levels of uncertainty (see Fig. 1 in Frame and Gray, 2010). A robust and statistically significant signal is extracted at $1 \mathrm{hPa}$ using a $15-20 \mathrm{yr}$ window, which is covered by stratospheric observational records. At $10 \mathrm{hPa}$, WACCM shows a significant warming of $0.4 \pm 0.2 \mathrm{~K}$ obtained, whereas ERA-40 and ERAInterim data show no significant response. This difference is possibly due to the different (longer) period analyzed in our study.

Between 30 and $70 \mathrm{hPa}$ a significant warming of $0.5-$ $0.7 \pm 0.3 \mathrm{~K}$ is diagnosed in WACCM, which agrees with values reported from ERA-40/ERA-Interim reanalysis in Frame and Gray (2010). Similar numbers are also calculated from MERRA reanalysis at 30,50 , and $70 \mathrm{hPa}$ using the same MLR technique over the same period (1979-2004; see Figs. 10c-e). Almost half of the temperature increase in this region is due to the use of a $1 \mathrm{yr}$ lag in the UV index, since a warming of 0.3 to $0.4 \mathrm{~K}$ is obtained when using a standard MLR without a lagged UV index (Fig. 7).

It is clear from Fig. 6 that the warming at $30 \mathrm{hPa}$ and lower levels disappears in the set without volcanic forcing, which suggests that aliasing of the volcanic aerosol signal increases the apparent solar signal. Further evidence of this comes from the increase in the UV regression coefficient when the boundaries of the data window considered for regression analysis overlap the years of the Mt. Pinatubo and El Chichón eruptions (Fig. 10c-e). There is also a tendency towards smaller values of the UV regression coefficient in the lower stratosphere $(50-70 \mathrm{hPa})$ as more years are added to the analysis, although no convergence towards a stable value is obtained even with a $45 \mathrm{yr}$ window. This indicates that it is not feasible to extract a robust signal in this region over the recent past. The spurious contribution of volcanic aerosols to the UV regression coefficient is especially pronounced when using records covering two to three decades, as in MERRA reanalysis data (see Fig.11). Better separation of solar and volcanic signals in temperature can be achieved by excluding El Chichón and Mt. Pinatubo posteruption data from the analysis, since convergence toward a stable (though non-significant) signal is obtained in this way (shown in Fig. 12). Additionally, extending the observational data record to cover solar cycles without volcanic eruptions coincident with peaks of solar activity (e.g., solar cycle 23) decreases the apparent solar-induced warming in the middle and lower tropical stratosphere. This is seen when regressing onto a $31 \mathrm{yr}$ long ERA-Interim/ERA-40 merged data set of 1978-2008 instead of the $23 \mathrm{yr}$ long ERA-40 data set of 1979-2001 (Frame and Gray, 2010, their Fig. 1).

The ozone increase of $2.0 \pm 0.7 \%$ in the upper stratosphere at solar maximum in the all forcings WACCM simulation agrees well with the Solar Backscatter Ultraviolet Instrument (SBUV) and Stratospheric Aerosol and Gas Experiment (SAGE) observations (Soukharev and Hood, 2006; Randel and $\mathrm{Wu}, 2007)$. An increase of similar magnitude is also obtained using a standard MLR (Fig. 9), which is the more akin to the technique used to extract the signal in the mentioned observational studies than the new MLR formulated here. The response at these levels is robust, since it is stable over time, and it is also diagnosed in the idealized experiments. An accurate estimate can be extracted with 20 $25 \mathrm{yr}$ of data, which is a window covered by satellite data. A relative minimum response in tropical ozone is diagnosed in WACCM around $30 \mathrm{hPa}$. This structure resembles the nonsignificant negative response seen at $10-20 \mathrm{hPa}$ in SBUV and SAGE (Soukharev and Hood, 2006; Randel and Wu, 2007). The mismatch in the height of the relative minimum response from model and satellite estimates is due to the different formulation of the regression method, since the standard MLR yields a higher relative minimum ( $20 \mathrm{hPa}$; see Fig. 9).

A significant ozone increase is found in the lower stratosphere between 40 and $100 \mathrm{hPa}$, with values ranging from $2.2 \pm 1.2 \%$ at $50 \mathrm{hPa}$ to $3.5 \pm 2.0 \%$ at $80 \mathrm{hPa}$. Similar numbers have been previously reported for the same period covered by SAGE and SBUV data (see Fig. 12a in Randel and Wu, 2007, and Fig. 8 in Soukharev and Hood, 2006), although no comparison with these studies is possible below $50 \mathrm{hPa}$, as this is the lowest boundary in the available satellite data of stratospheric ozone. Idealized experiments show that ENSO aliasing in the lower-stratospheric ozone signal is negligible. This is due to the new MLR technique, which combines the use of lagged ENSO and UV terms, and to a sufficiently large window of $45 \mathrm{yr}$, which is in line with the findings of Marsh and Garcia (2007). On the other hand, it is also found that the apparent solar cycle ozone increase in the lower stratosphere is strongly influenced by volcanic aerosols and, to a lesser extent, by the presence of the QBO. Interference with volcanic eruptions is also indicated by the increase in the UV regression coefficient when the data window overlaps periods shortly after Mt. Pinatubo and El Chichón eruptions (Fig. 13c-e). Our results confirm the findings from a study using a more simplified 2-D transport chemistry model that pointed to a strong contribution of the QBO and volcanic aliasing on the tropical ozone solar signal (Lee and Smith, 2003; Smith and Matthes, 2008).

We note that around $20 \mathrm{hPa}$ a consistent bias is seen in both temperature and ozone related to the problem of volcanic heating aliasing. Specifically, it appears that a fraction of the volcanic-induced heating is misattributed to the solar cycle by the new and standard MLR techniques, thus producing warmer temperatures during solar maximum. This diabatic heating produces stronger upwelling rates in the simulations including all observed forcings compared to the set excluding volcanic forcing. Along with the chemically induced ozone depletion by the sulfate aerosols, the increased upwelling results in an ozone decrease due to the strongly positive vertical gradient in ozone mixing ratio, which the regression also attributes to the solar cycle, leading to a weaker solar cycle ozone response relative to the set excluding volcanic aerosols. On the other hand, the spurious contribution of volcanic aliasing to the apparent solar signal in both temperature 
and ozone below $50 \mathrm{hPa}$ is more difficult to be explained in these terms. At these levels, the simulated ozone depletion is generally much weaker than at $20-30 \mathrm{hPa}$, as was, for example, the case for the Mt. Pinatubo eruption (see Fig. 8.21 in CCMVal-2, 2010). Moreover, the regression fits from the new technique described in Eq. (A6) are carried independently for temperature and ozone. Thus, the misattribution of volcanically induced ozone and temperature changes cannot be expected to have opposite sign throughout the lower stratosphere.

Chiodo et al. (2012) showed that the temperature and ozone signal in the TLS estimated is stronger and closer to observations in the WACCM3.5 model than in the WACCM3.1 version. The improvement is likely a consequence of WACCM3.1 not assimilating a QBO and the omission of volcanic aerosol heating in the simulations (Garcia et al., 2007). Consequently, the QBO and volcanic signals did not map into the $11 \mathrm{yr}$ solar cycle in the regression analysis of transient WACCM3.1 simulations, leading to a worse agreement compared to transient WACCM3.5 simulations. However, the better agreement with observations does not necessarily imply a better estimate of the solar signal. In conclusion, the present results suggest that either given a long enough window, or in idealized experiments excluding the spurious contribution of volcanic aerosols in the analysis, a consistent, though weaker than previously thought, solar response is diagnosed in the tropical lower stratosphere.

Finally, it is important to note the caveat of excessive heating caused by the Mt. Pinatubo eruption in the TLS region (see Fig.1), although the precise size of the bias is difficult to assess as the uncertainty in the response derived from observations is not known. An excessive volcanic warming could have possibly contributed to the aliasing of the apparent solar signal. However, it must also be noted that the oversized heating could be due to errors in the SAD aerosol forcing data set recommended by CCMVal (Arfeuille et al., 2013). As such, this is a common bias in many community climate models (see, for example, Fig 8.21 in CCMVal-2, 2010). Depending on how the radiative transfer is handled, this affects the models sensitivity to volcanic aerosols to a greater or lesser degree than in WACCM. Thus, while there may be caveats in comparing modeled and observed MLR-derived attribution of decadal variability, our findings are likely not limited to WACCM.

\section{Summary}

We have investigated the attribution of quasi-decadal variations in tropical stratospheric temperature and ozone to the $11 \mathrm{yr}$ solar cycle. To do so, we perform a set of transient WACCM3.5 simulations with different combination of forcings. The solar signal is extracted from the model simulations using a new MLR approach, which (i) reduces the autocorrelation through prewhitening and (ii) improves the ac- curacy of the fit through the use of an optimal lag. Results are also compared to the standard MLR, which is found to be more prone to aliasing from non-solar sources than the new MLR method. The design of the model experiments employed here is more realistic than previous modeling studies on the impact of aliasing on the detection of the solar signal, e.g., Marsh and Garcia (2007). The main findings are as follows:

- A double-peak profile in both temperature and ozone with maxima in the upper and lower stratosphere is diagnosed in the WACCM3.5 simulations forced with all observed forcings. This agrees qualitatively well with reanalysis and satellite data.

- In the tropical lower stratosphere, a substantial portion of the apparent solar-induced increase in temperature and ozone is related to volcanic aerosol. This is due to alignment of two major volcanic eruptions (El Chichón and Mt. Pinatubo) with peaks of solar activity during cycles 21 and 22.

- Using $45 \mathrm{yr}$ of data, a robust $11 \mathrm{yr}$ solar signal can only be extracted above $10 \mathrm{hPa}$. At lower levels, longer records would be required. This occurs because the solar and volcanic signals cannot be adequately separated.

- The aliasing issue is ameliorated if windows around $\mathrm{El}$ Chichón and Mt. Pinatubo are excluded from the analysis (June 1982 to November 1983, and September 1991 to November 1993). This removal reduces the apparent solar signal in temperature in both modeled and observational data. In ozone, further complication is caused by interference with the QBO.

It is plausible that the observed amplitude of the solarinduced increase in the TLS in temperature and ozone (as reported in other studies, $0.8 \mathrm{~K}$ in reanalysis (Frame and Gray, 2010) and $4 \%$ in satellite data (Soukharev and Hood, 2006)) is overestimated due to issues associated with the MLR analysis of a too short record that have been explored in this work.

The present results suggest that MLR techniques require the use of longer observational records for unambiguous separation of decadal changes driven by the solar cycle. When regressing reanalysis and satellite data that are available to date (e.g., MERRA reanalysis data spanning over $26 \mathrm{yr}$ ), both windows around El Chichón and Mt. Pinatubo should be removed for more accurate determination of the solar signal. 


\section{Appendix A:}

The standard version of multiple linear regression models takes the following form:

$Y_{t}=\sum_{i=1}^{n} \mathbf{X}_{i, t} \beta_{i}+\epsilon_{t}$,

where $Y$ is the predictand (i.e., the dependent variable), $t$ is the time dimension, $\mathbf{X}$ is a matrix with the basis functions containing $n$ predictors, $\beta$ represents the regression coefficients, and $\epsilon$ is the residual error term.

Multiple linear regression models after Eq. (A1) are commonly used in solar cycle studies. The $\mathbf{X}$ matrix typically contains a set of predictors representing possible sources of variability: a linear trend term for long-term changes due to increases in GHGs and ozone-depleting substances, and a set of proxy indices for ENSO, the $11 \mathrm{yr}$ solar cycle, the QBO, and volcanic eruptions.

Valuable information about the impact of each forcing can be extracted with this method, provided that the correct portion of variance in the predictand time series is fit, along with its relative attribution to each of the predictors. However, this is not the case when the predictors in matrix $\mathbf{X}$ are cross correlated ("multi-collinearity"), and when there is autocorrelation in the predictand time series ("persistence") (Wilks, 2011). Spurious correlations with the predictors can arise due to persistence in the predictand time series, while multicollinearity leads to erroneous partitioning of the variance among predictors. Collinearity between the predictors can be significant, especially in relatively short records; an example is the correlation found between the N3.4 index and the 11 yr solar cycle (Marsh and Garcia, 2007). Additionally, significant persistence can be found within seasonal timescales in atmospheric field variables, which implies that individual data points in the predictand are not independent.

A common way to circumvent the problem associated with persistence is to treat the residual error term in the regression model as an autoregressive process (Tiao et al., 1990). This method implies correction of both the basis functions in $\mathbf{X}$ and the predictand $Y$ with the autocorrelation coefficient of the residual error term $\epsilon$ estimated from a first application of the regression model. This intermediate step is called "prewhitening", and its application can be found in numerous papers on the solar signal in the stratosphere (e.g., Soukharev and Hood, 2006; Austin et al., 2008; Frame and Gray, 2010). Another way to account for autocorrelation is by prewhitening the predictand $Y$ and predictors $\mathbf{X}$ with the first-order autocorrelation coefficient of the original time series of the predictand $Y$. This is the so-called Box-Jenkins (BJ) methodology (Box and Jenkins, 1980).

Both prewhitening techniques were carried out on the output from the WACCM model. It was found that the BJ prewhitening leads to an autocorrelation function (ACF) that is closer to white noise (not shown) and hence optimal for regression analysis (Box and Jenkins, 1980). Hence, the BJ technique was chosen for the analysis of the simulations presented in this paper.

Once the time series have been prewhitened, the regression model equation is carefully assessed upon analysis of the lagged cross-correlation structures between the predictors (i.e., the $i$ time series in the $\mathbf{X}$ matrix) and the predictand $Y$. This is done to identify the lags that maximize the projection of variance onto the basis functions, improving the fit accuracy.

We performed a preliminary analysis by using both (i) deseasonalized monthly mean, (ii) seasonal mean (3-month averages), and (iii) 3-month running mean anomalies of temperature and ozone. It is found that the use of (ii) seasonal averages filters spurious cross-correlation structures showing up at high frequencies (1-2 months) that are related to internal noise rather than a causal relationship. Therefore, seasonal mean anomalies are used in this analysis. The use of seasonal averages is also justified physically. Part of the changes in stratospheric temperature and ozone due to ENSO, QBO, and solar cycle are mediated by changes in upwelling rates, especially in the TLS. Randel et al. (2002) showed that coherence between temperature and upwelling rates in the TLS is enhanced at seasonal timescales compared to higher frequencies, so that dynamically forced changes in temperature can be better captured with seasonal averages.

In the reference all forcings ensemble, the matrix $\mathbf{X}$ reads as follows:

$\mathbf{X}=\left(\begin{array}{c}t \\ N 3.4 \\ \mathrm{UV} \\ u 30 \\ u 10 \\ \mathrm{SAD}\end{array}\right)$,

where $t$ is the time dimension in seasons; $N 3.4$ is the Niño 3.4 index (the standardized mean sea surface temperature between $5^{\circ} \mathrm{S}$ and $5^{\circ} \mathrm{N}$ latitude and between 120 and $170^{\circ} \mathrm{W}$ longitude) for ENSO; UV is the ultraviolet solar radiation flux integrated in the Hartley band (240-270 nm) from the Lean dataset (Lean et al., 2005), and is used as a proxy for the $11 \mathrm{yr}$ solar cycle; and $u 30$ and $u 10$ are the equatorial zonal mean zonal winds at 30 and $10 \mathrm{hPa}$, which have the quality of being nearly orthogonal proxies for the QBO (Randel and $\mathrm{Wu}, 1996)$. SAD is the global mean surface area density at $50 \mathrm{hPa}$ (in units of $\mu \mathrm{m}^{2} \mathrm{~cm}^{-3}$ ) of sulfate aerosol taken from a combination of different datasets: SAGE I (19791981), SAGE II (1984-2005), and SME instruments. Aerosol data before 1979 are constructed based on assumptions of background aerosol (see Sect. 2.5.3.4 of CCMVal-2, 2010). Based on SAD, an aerosol mass distribution is assumed in WACCM3.5 for heating rate calculations (Tilmes et al., 2009). Hence, this dataset is the most appropriate proxy for the volcanic forcing in the model simulations. 
When using data from the idealized ensembles, the forcings that are kept constant (following table 1) are removed from the $\mathbf{X}$ matrix. The N3.4 index is excluded in the fixedSSTs ensemble, $u 10$ and $u 30$ are excluded in the noQBO ensemble, while the SAD index is excluded in the noVOLC ensemble.

The first step in the formulation of the regression model is prewhitening of both sides of Eq. (A1):

$Y_{t, z}^{\prime}=Y_{t, z}-\rho_{z} Y_{t-1, z}$

$\mathbf{X}_{t, i, z}^{\prime}=\mathbf{X}_{t, i, z}-\rho_{z} \mathbf{X}_{t-1, i, z}$

where $\rho_{z}$ is the autocorrelation coefficient of $Y$ at lag of one season and at the level $z$, and $i$ is the forcing index. Equation (A3) is applied at each discrete model level $z$ ranging from 0.1 to $100 \mathrm{hPa}$. It is found that the use of the autocorrelation at lag 1 is enough to reduce the ACF of $Y^{\prime}$ to white noise, so that there is no need to use autoregressive models of higher order.

After prewhitening both forcings and seasonal mean anomalies of temperature and ozone, we calculate the lag $\tau$ at which the absolute value of the cross correlation between each predictor $i$ and $Y^{\prime}$ reaches a maximum value at a given level $z$.

$\tau_{i, z}=t \| r\left(Y_{t=0 \ldots n, z}^{\prime}, \mathbf{X}_{i, t=0+\tau \ldots n, z}^{\prime}\right)=\mathrm{MAX}$

A separate analysis showed that no significant cross correlation between predictors is introduced by using the $1 \mathrm{yr}$ window. Furthermore, correlations arising at lags larger than the characteristic timescale of each forcing are unlikely to describe a physical link with the dependent variable. This is especially true in the stratosphere, where the responses are not modulated by the ocean.

In the case of the QBO, the indices $u 30^{\prime}$ and $u 10^{\prime}$ are approximately sinusoidal and nearly orthogonal to each other. As such, the use of different lags would introduce correlations between them, and therefore loss of orthogonality. The most accurate fit is obtained by computing the regression coefficient, and hence without using any lag in any of the QBO indices. This motivates a different treatment of the $\mathrm{QBO}$ in Eq. (A4) compared to the other terms, i.e. by using $\tau_{\mathrm{qbo}}=0$.
An additional complication is posed by the separation of QBO signals from the other sources of variability. We found that the observed zonal wind that is assimilated in the ensembles including a QBO contains significant variations arising from volcanoes, ENSO, and solar cycle. For the solar cycle, this result is consistent with the reported modulation of the QBO periodicity by the solar cycle (Salby and Callaghan, 2000). We remove the collinearity by computing two filtered QBO indices. For this purpose, we regress the UV, ENSO, and SAD indices using their optimal lag $\tau$ on zonal mean wind at both 30 and $10 \mathrm{hPa}$, and take the residual as filtered QBO index, as described by Eq. (A5):

$$
\begin{aligned}
& u 30_{t, z}^{*}=u 30_{t, z}^{\prime}-\left(\beta_{\mathrm{uv}} \mathrm{UV}_{t-\tau_{i=\mathrm{uv}, z}, z}^{\prime}\right. \\
& \left.+\beta_{\mathrm{enso}} N 3.4_{t-\tau_{i=\mathrm{enso}, z}, z}^{\prime}+\beta_{\mathrm{volc}} \mathrm{SAD}_{t-\tau_{i=\mathrm{volc}, z}, z}^{\prime}\right) \\
& u 10_{t, z}^{*}=u 10_{t, z}^{\prime}-\left(\beta_{\mathrm{uv}} \mathrm{UV}_{t-\tau_{i=\mathrm{uv}, z}, z}^{\prime}\right. \\
& \left.+\beta_{\mathrm{enso}} N 3.4_{t-\tau_{i=\mathrm{enso}, z}, z}^{\prime}+\beta_{\mathrm{volc}} \mathrm{SAD}_{t-\tau_{i=\mathrm{volc}, z}, z}^{\prime}\right) .
\end{aligned}
$$

In this way, $u 30^{*}$ and $u 10^{*}$ are made orthogonal with respect to the other indices while preserving their mutual orthogonality by excluding any QBO lag. This improves the accuracy of the regression analysis. The two filtered QBO indices, along with the prewhitened and lagged predictors, are then used in the target regression model for ozone and temperature.

$$
\begin{aligned}
& Y_{t, z}^{\prime}=\beta_{\mathrm{uv}}^{\prime} U V_{t-\tau_{i=\mathrm{uv}, z}, z}^{\prime}+\beta_{\mathrm{enso}}^{\prime} N 3.4_{t-\tau_{i=\mathrm{ens}, z}, z}^{\prime}+\beta_{\mathrm{qbo1}}^{\prime} u 30_{t, z}^{*} \\
& +\beta_{\mathrm{qbo} 2}^{\prime} u 10_{t, z}^{*}+\beta_{\mathrm{volc}}^{\prime} \mathrm{SAD}_{t-\tau_{i=\mathrm{vol}, z}, z}^{\prime}+e_{t, z}^{\prime}
\end{aligned}
$$

For the regression of ozone, the regression coefficients $\beta^{\prime}$ are given in relative percentage units. First, we regress absolute values of tropical mean mixing ratio, and then the percentages are taken on the long-term climatology.

The regression model described by Eq. (A6) is used in the analysis of the reference all forcings set. In the idealized sets, the forcings that are kept fixed are excluded from Eq. (A6). 
Acknowledgements. The authors thank J. Añel, K. Matthes, and J. Richter for performing two of the simulations. The authors are grateful for the support with high-performance computing from Yellowstone (ark:/85065/d7wd3xhc), provided by NCAR's Computational and Information System Laboratory, sponsored by the National Science Foundation. Computing resources were also provided by the Barcelona Supercomputing Center (BSC), Centro Extremeño de iNvestigación, Innovación Tecnológica y Supercomputacion (CENITS), and Centro de Supercomputación de Galicia (CESGA). The authors thankfully acknowledge the technical expertise and assistance provided by BSC, CENITS, and CESGA for carrying out the model simulations in the MareNostrum, Lusitania, and Finisterrae supercomputers. The authors also acknowledge the European COST Action ES1005. G. Chiodo was supported by the Spanish Ministry of Education in the framework of the FPU doctoral fellowship (grant AP2009-0064).This work was also supported by the Spanish Ministry of Science and Innovation (MCINN) through the CONSOLIDER (CSD200700050-II-PR4/07) and MATRES (CGL2012-34221) projects. The National Center for Atmospheric Research is operated by the University Corporation for Atmospheric Research with sponsorship of the National Science Foundation.

Edited by: P. Jöckel

\section{References}

Arfeuille, F., Luo, B. P., Heckendorn, P., Weisenstein, D., Sheng, J. X., Rozanov, E., Schraner, M., Brönnimann, S., Thomason, L. W., and Peter, T.: Modeling the stratospheric warming following the Mt. Pinatubo eruption: uncertainties in aerosol extinctions, Atmos. Chem. Phys., 13, 11221-11234, doi:10.5194/acp13-11221-2013, 2013.

Austin, J., Tourpali, K., Rozanov, E., Akiyoshi, H., Bekki, S., Bodeker, G., Brühl, C. Butchart, N., Chipperfield, M., Deushi, M., Fomichev, V. I., Giorgetta, M. A., Gray, L., Kodera, K., Lott, F., Manzini, E., Marsh, D., Matthes, K., Nagashima, T., Shibata, K., Stolarski, R. S., Struthers, H., and Tian, W.: Coupled chemistry climate model simulations of the solar cycle in ozone and temperature, J. Geophys. Res., 113, 1-20, doi:10.1029/2007JD009391, 2008.

Baldwin, M., Gray, L. J., Dunkerton, T. J., Hamilton, K., Haynes, P. H., Randel, W. J., Holton, J. R., Alexander, M. J., Hirota, I., Horinouchi, T., Jones, D. B. A., Kinnersley, J. S., Marquardt, C., Sato, K., and Takahashi, M.: The quasi-biennial oscillation, Rev. Geophys., 39, 179-230, 2001.

Bisgaard, S. and M. Kulahci: Time Series Analysis and Forecasting by Example, vol. 815, Wiley, Singapore, 2011.

Box, G., and Jenkins, G.: Time Series Analysis. Forecasting and Control, Holder Day, San Francisco, 1980.

Calvo, N., Garcia, R., Randel, W., and Marsh, D. R.: Dynamical mechanism for the increase in tropical upwelling in the lowermost tropical stratosphere during warm enso events, J. Atmos. Sci., 67, 2331-2340, 2010.

CCMVal-2: SPARC CCMVal Report on the Evaluation of Chemistry-Climate Models, edited by: Eyring, V., Shepherd, T. G., and Waugh, D. W., Tech. rep., SPARC Report No. 5, WCRP-132, WMO/TD-1526, World Meteorological Organization, Geneva, 2010.
Chiodo, G., Calvo, N., Marsh, D. R., and Garcia-Herrera, R.: The 11 year solar cycle in transient WACCM3.5 simulations, J. Geophys. Res., 117, D06109, doi:10.1029/2011JD016393, 2012.

Crooks, S. and Gray, L.: Characterization of the 11-year solar signal using a multiple regression analysis of the ERA-40 dataset, J. Climate, 18, 996-1015, doi:10.1175/JCLI-3308.1, 2005.

Diaz, J., Garcia, R., De Castro, F. V., Hernández, E., López, C., and Otero, A.: Effects of extremely hot days on people older than 65 years in seville (Spain) from 1986 to 1997, Int. J. Biometeorol., 46, 145-149, 2002.

Diaz, J., Jordán, A., García, R., López, C., Alberdi, J., Hernández, E., and Otero, A.: Heat waves in madrid 1986-1997: effects on the health of the elderly, Int. Arch. Occ. Env. Hea., 75, 163-170, 2002.

Eyring, V., Cionni, I., Bodeker, G. E., Charlton-Perez, A. J., Kinnison, D. E., Scinocca, J. F., Waugh, D. W., Akiyoshi, H., Bekki, S., Chipperfield, M. P., Dameris, M., Dhomse, S., Frith, S. M., Garny, H., Gettelman, A., Kubin, A., Langematz, U., Mancini, E., Marchand, M., Nakamura, T., Oman, L. D., Pawson, S., Pitari, G., Plummer, D. A., Rozanov, E., Shepherd, T. G., Shibata, K., Tian, W., Braesicke, P., Hardiman, S. C., Lamarque, J. F., Morgenstern, O., Pyle, J. A., Smale, D., and Yamashita, Y.: Multimodel assessment of stratospheric ozone return dates and ozone recovery in CCMVal-2 models, Atmos. Chem. Phys., 10, 94519472, doi:10.5194/acp-10-9451-2010, 2010.

Calvo-Fernández, N. C., Garcia-Herrera, R., Puyol, D. G., Hernandez, E., GarcÍa, R., Gimeno, L., and Ribera, P.: Analysis of the enso signal in tropospheric and stratospheric temperatures observed by msu, 1979-2000, J. Climate, 17, 3934-3946, 2004.

Frame, T. and Gray, L.-J.: The 11-year solar cycle in era-40 data: an update to 2008, J. Climate, 23, 2213-2222, 2010.

Garcia, R., Marsh, D. R., Kinnison, D., Boville, B., and Sassi, F.: Simulation of secular trends in the middle atmosphere, 1950-2003, J. Geophys. Res., 112, D09301, doi:10.1029/2006JD007485, 2007.

Gray, L., Beer, J., Geller, M., Haigh, J. D., Lockwood, M., Matthes, K., Cubasch, U., Fleitmann, D., Harrison, G., Hood, L., Luterbacher, J., Meehl, G. A., Shindell, D., Van Geel, B., and White, W.: Solar influences on climate, Rev. Geophys., 48, RG4001, doi:10.1029/2009RG000282, 2010.

Haigh, J. and Blackburn, M.: Solar influences on dynamical coupling between the stratosphere and troposphere, Space Sci. Rev., 125, 331-344, 2006.

Hood, L.: The solar cycle variation of total ozone: Dynamical forcing in the lower stratosphere, J. Geophys. Res., 102, 1355-1370, 1997.

Hood, L. and Soukharev, B.: Quasi-decadal variability of the tropical lower stratosphere: The role of extratropical wave forcing, J. Atmos. Sci., 60, 2389-2403, 2003.

Hood, L., Soukharev, B., and McCormack, J.: Decadal variability of the tropical stratosphere: Secondary influence of the el niño-southern oscillation, J. Geophys. Res., 115, D11113, doi:10.1029/2009JD012291, 2010.

Hurrell, J. W., Hack, J. J., Shea, D., Caron, J. M., and Rosinski, J.: A new sea surface temperature and sea ice boundary dataset for the community atmosphere model, J. Climate, 21, 5145-5153, 2008.

Kodera, K. and Kuroda, Y.: Dynamical response to the solar cycle, J. Geophys. Res., 107, 4749, doi:10.1029/2002JD002224, 2002. 
Lean, J., Rottman, G., Harder, J., and Kopp, G.: Sorce contributions to new understanding of global change and solar variability, The Solar Radiation and Climate Experiment (SORCE), Sol. Phys., 230, 27-53, 2005.

Lee, H. and Smith, A.: Simulation of the combined effects of solar cycle, quasi-biennial oscillation, and volcanic forcing on stratospheric ozone changes in recent decades, J. Geophys. Res., 108, D24049, doi:10.1029/2001JD001503, 2003.

Marsh, D. R. and Garcia, R.: Attribution of decadal variability in lower-stratospheric tropical ozone, Geophys. Res. Lett., 34, L21807, doi:10.1029/2007GL030935, 2007.

Matthes, K., Marsh, D., Garcia, R., Kinnison, D., Sassi, F., and Walters, S.: Role of the QBO in modulating the influence of the 11 year solar cycle on the atmosphere using constant forcings, J. Geophys. Res., 115, D18110, doi:10.1029/2009JD013020, 2010.

Meehl, G., Arblaster, J., Matthes, K., Sassi, F., and van Loon, H.: Amplifying the Pacific Climate System Response to a Small 11Year Solar Cycle Forcing, Science, 325, 1114-1118, 2009.

Pap, J. and Fox, P.: Solar variability and its effects on climate, Washington DC American Geophysical Union Geophysical Monograph Series, 141, 356 pp., doi:10.1029/141GM, 2004.

Randel, W. J., Wu, F., Russell, J., Waters, J., and Froidevaux, L.: Ozone and temperature changes in the stratosphere following the eruption of mount pinatubo, J. Geophys. Res., 100, 1675316764, 1995.

Randel, W. and Wu, F.: Isolation of the Ozone QBO in SAGE 2 Data by Singular-Value Decomposition, J. Atmos. Sci., 53, 2546-2560, 1996.

Randel, W. J., Garcia, R. R., and Wu, F.: Time-dependent upwelling in the tropical lower stratosphere estimated from the zonal-mean momentum budget, J. Atmos. Sci., 59, 2141-2152, 2002.

Randel, W. and Wu, F.: A stratospheric ozone profile data set for 1979-2005: Variability, trends, and comparisons with column ozone data, J. Geophys. Res, 112, D06313, doi:10.1029/2006JD007339, 2007.

Randel, W., Garcia, R., Calvo, N., and Marsh, D.: ENSO influence on zonal mean temperature and ozone in the tropical lower stratosphere, Geophys. Res. Lett, 36, L15822, doi:10.1029/2009GL039343, 2009.

Randel, W. J., Shine, K. P., Austin, J., Barnett, J., Claud, C., Gillett, N. P., Keckhut, P., Langematz, U., Lin, R., Long, C., Mears, C., Miller, A., Nash, J., Seidel, D. J., Thompson, D. W. J., Wu, F., and Yoden, S.: An update of observed stratospheric temperature trends, J. Geophys. Res., 114, D02107, doi:10.1029/2008JD010421, 2009.
Rienecker, M. M., Suarez, M. J., Gelaro, R., Todling, R., Bacmeister, J., Liu, E., Bosilovich, M. G., Schubert, S. D., Takacs, L., Kim, G.-K. Bloom, S., Chen, J., Collins, D., Conaty, A., Da Silva, A., Gu, W., Joiner, J., Koster, R.D., Lucchesi, R., Molod, A., Owens, T., Pawson, S., Pegion, P., Redder, C.R., Reichle, R., Robertson, F.R., Ruddick, A.G., Sienkiewicz, M., and Woolen, J.: Merra: Nasa's modern-era retrospective analysis for research and applications, J. Climate, 24, 3624-3648, 2011.

Robock, A.: Volcanic eruptions and climate, Rev. Geophys., 38, 191-219, 2000.

Salby, M. and Callaghan, P.: Connection between the solar cycle and the qbo: The missing link, J. Climate, 13, 2652-2662, 2000.

Schmidt, H., Brasseur, G., and Giorgetta, M.: Solar cycle signal in a general circulation and chemistry model with internally generated quasi biennial oscillation, J. Geophys. Res., 115, D00I14, doi:10.1029/2009JD012542, 2010.

Smith, A. and Matthes, K.: Decadal-scale periodicities in the stratosphere associated with the solar cycle and the QBO, J. Geophys. Res., 113, D05311, doi:10.1029/2007JD009051, 2008.

Soukharev, B. and Hood, L.: Solar cycle variation of stratospheric ozone: Multiple regression analysis of long-term satellite data sets and comparisons with models, J. Geophys. Res., 111, D20314, doi:10.1029/2006JD007107, 2006.

Thomason, L., Poole, L., and Deshler, T.: A global climatology of stratospheric aerosol surface area density deduced from stratospheric aerosol and gas experiment ii measurements: 1984-1994, J. Geophys. Res.,102, 8967-8976, 1997.

Tiao, G., Reinsel, G., Xu, D., Pedrick, J., Zhu, X., Miller, A., DeLuisi, J., Mateer, C., and Wuebbles, D.: Effects of autocorrelation and temporal sampling schemes on estimates of trend and spatial correlation, J. Geophys. Res., 95, 20507-20517, 1990.

Tilmes, S., Garcia, R., Kinnison, D., Gettelman, A., and Rasch, P.: Impact of geoengineered aerosols on the troposphere and stratosphere, J. Geophys. Res., 114, D12305, doi:10.1029/2008JD011420, 2009.

Wilks, D. S.: Statistical methods in the atmospheric sciences, vol. 100, Academic press, Oxford, 2011. 